2. To: (Receiving organization)

Factlity Operations Design

Authority

5. Proj./Prog./Dept. /Oix.:

TWRS Safety \& Licensing

8. Originator Remarks:

Approva1/Release

11: Receiver Remarks
3. from: (Originating organization) TWRS FSAR Development

6. Design Authority/ Design Agent/Cog. Engr.: L.J. Ju]yk/F.C. Han
4. Related EDT No.:

$N / A$

7. Purchase Order No.:

$\mathrm{N} / \mathrm{A}$

9. Equip./Component No.:

N/A

10. System/Bldg./Facility: HANFORD WASTE TANKS

12. Major Assm. Dwg. No.:

$N / A$

13. Permit/Permit Application No.: N/A

14. Required Response Date:

$N / A$

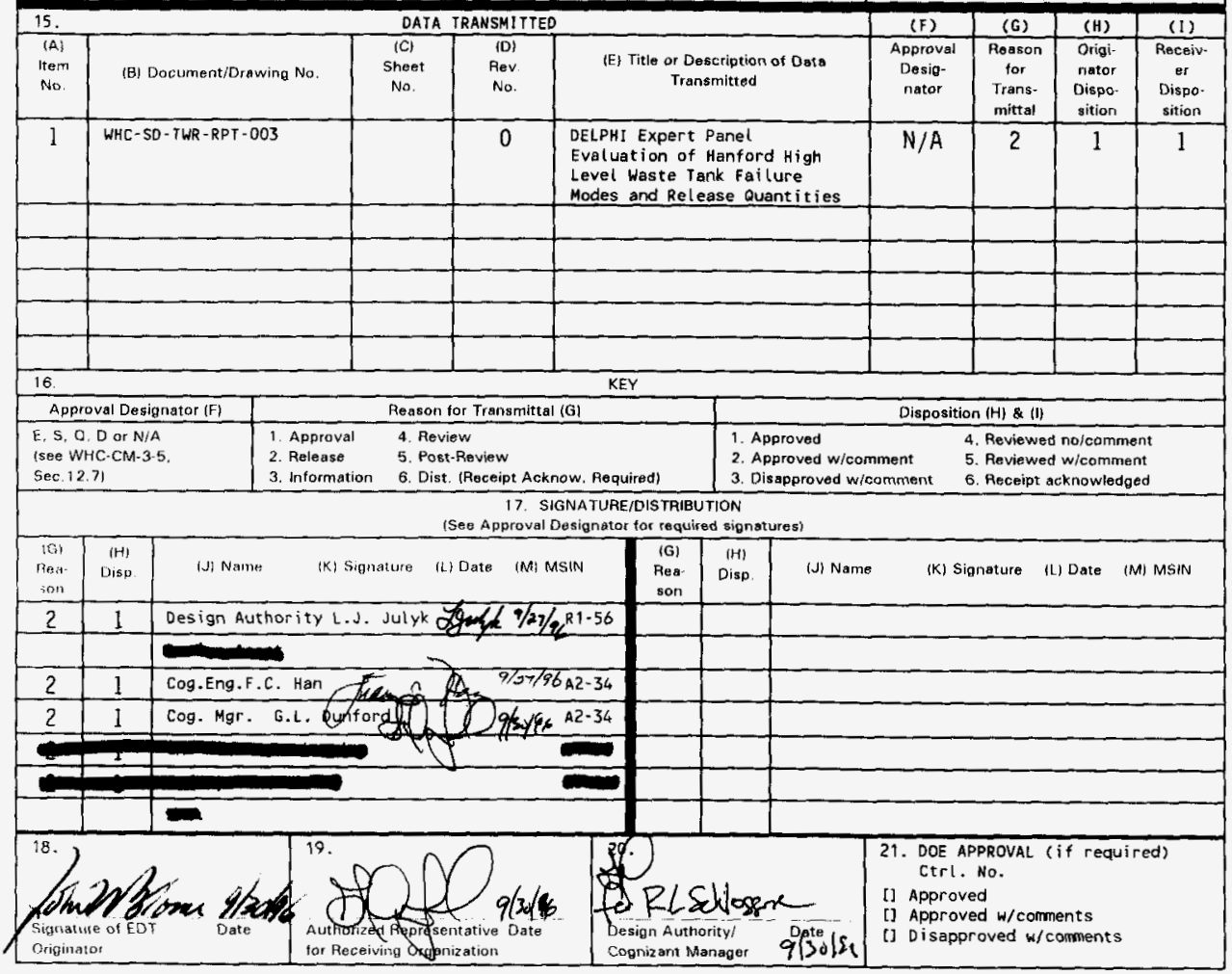

BD-7400-172-2(05/96) GEF09? 


\title{
DELPHI Expert Panel Evaluation of Hanford High Level Waste Tank Failure Modes and Release Quantities
}

\author{
F. C. Han
}

Westinghouse Hanford Company, Richland, WA 99352

U.S. Department of Energy Contract DE-AC06-87RLI0930

\author{
EDT/ECN: EDT 606489 \\ Org Code: $74 \mathrm{E} 20$ \\ UC: 2030 \\ Org Code: 74E20 \\ Charge Code: N1FW3
}

Key Words: Experts, Opinion, Structural, Concrete, Steel, Accidents, Loads, Thermal, Seismic, Failure, Release, Quantity.

Abstract: The Failure Modes and Release Quantities of the Hanford High Level Waste Tanks due to postulated accident loads were established by a DELPHI Expert Panel consisting of both on-site and off-site experts in the field of Structure and Release. The Report presents the evaluation process, accident loads, tank structural failure conclusion reached by the panel during the two-day meeting.

TRADEMARK DISCLAIMER. Reference herein to any specific commercial product, process, or service by trade name, trademark, manufacturer, or otherwise, does not necessarily constitute or imply its endorsement, recommendation, or favoring by the United States Government or any agency thereof or its contractors or subcontractors.

Printed in the United States of America. To obtain copies of this document, contact: WHC/BCS Document Control Services, P.O. Box 1970, Mailstop H6-08, Richland WA 99352, Phone (509) 372-2420; Fax (509) 376-4989.
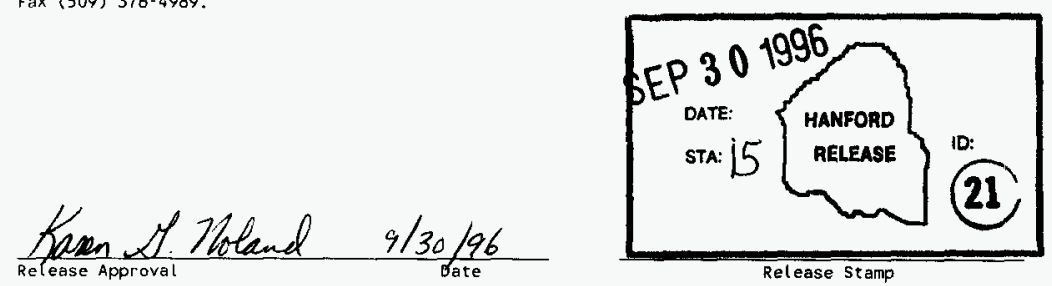

\section{Approved for Public Release}




\title{
DELPHI Expert Panel Evaluation of Hanford High Level Waste Tank \\ Failure Modes and Release Quantities
}

\author{
Compiled and edited by \\ Larry Leach \\ Contributors: \\ Release Sub-Panel \\ Peter Davis \\ Steve Eisenhower \\ Michael Hitchler \\ Larry Leach \\ Jofu Mishima \\ Charies Solbrig \\ Structural Sub-Panel \\ Jim Beavers \\ John Friley \\ Ray Gallucci \\ Francis C. Han \\ Larry Julyk \\ Moe Khaleel \\ Carletan Moore \\ Mark Scott \\ Evan Weiner \\ reviewed by \\ Dr. Robert Budnitz \\ FINAL VERSION \\ September 18, 1996
}




\section{Summary}

This report identifies and evaluates the dominant failure modes and quantity of waste released from the Hanford High Level Waste Tanks for postulated accidents in the Tank Waste Remediation System (TWRS) Final Safety Analysis Report (FSAR). The report will guide analysis for the TWVRS Manage Tank Waste FSAR. A panel of experts performed the analysis, initially using the Delphi method. This work supports the need to have a conservative yet reasonably bounding analysis.

Previous Westinghouse Hanford Company (WHC) analysis predicted the transfer of seven liters $(-10 \mathrm{~kg})$ of tank waste to the air from a tank accident that collapses the tank dome. More recent analysis by Los Alamos National Laboratory (LANL) predicted over $100 \mathrm{~kg}$ of waste may be available for air transport in similar accidents. The Delphi panel evaluated tank accidents leading to air release to clarify this difference.

Contrary to the panel's initial expectations, they concluded that collapse of the entire dome of a high level waste tank was not the dominant failure mode for the scenarios studied. Dominant failure modes for potential design basis accidents result in cracking. leaking, modest penetration, and a partial 'can-opener' opening in the dome as modes of failure important to air release.

The summary table presents the experts overall conclusions for failure modes and release quantities. These data satisfy the purpose and objectives (see section 1) by identifying the most significant tank failure modes and relative estimates of release quantities. The table shows that deflagration accidents are the only realistic accident type that can deliver significant off-site doses. The failure limits for excessive dome loading are so high that the hazard analy'sis may classify these accidents as beyond extremely unlikely. The panel concluded aging is not a separate initiator, but aged material properties should be considered in the other Safely analysis.

The panel calculated air releate quantities far below either of the previous two analyses. This is becatuse boln of the previous andysis were basid on an issumplion of total dome 
WHC-SD-TWR-RPT-003, Rev, 0

nFI PHi Funart Damal F aliatinn if Hanined High Level Waste Tank

Failure Modes and Release Quantities

collapse as the failure mode. The panel based their calculations on realistic failure modes for concrete structures, supported by world data and extensive previous stress analysis of Hanford tanks.

Summary Table:

Delphi expert panel estimated failure modes and releases.

\begin{tabular}{|c|c|c|c|}
\hline Accident Initiator & Failure Mode(s) & Failure Loads & Release Quantities \\
\hline Load drop & Local penetration & $200,000 \mathrm{ft}-\mathrm{lb}$ & Negligible \\
\hline $\begin{array}{l}\text { Excessive dome } \\
\text { loading }\end{array}$ & $\begin{array}{l}\text { Uniform: } \\
\text { Haunch and dome } \\
\text { cracking } \\
\text { Concentrated: } \\
\text { Shear of } 10^{\prime} \text { radius } \\
\text { section }\end{array}$ & $\begin{array}{l}\text { Uniform: } 30 \mathrm{ft} \\
\text { additional over- } \\
\text { burden } \\
\text { Concentrated: } \\
\text { SST: } 300-600 \text { tons } \\
\text { DST: } 400-800 \text { tons }\end{array}$ & None \\
\hline Aging & $\begin{array}{l}\text { No unique modes for } \\
\text { air releases }\end{array}$ & $\begin{array}{l}\text { Modifies limits for } \\
\text { other initiators }\end{array}$ & $\mathrm{N} / \mathrm{A}$ \\
\hline $\begin{array}{l}\text { Gas or liquid } \\
\text { deflagration }\end{array}$ & $\begin{array}{l}\text { Haunch and dome } \\
\text { cracking to 'can- } \\
\text { opener' opening }\end{array}$ & $\begin{array}{l}\text { SSTs: } 11 \mathrm{psig} \\
\text { DSTs: } 60 \text { psig }\end{array}$ & $<1 \mathrm{~kg}$ \\
\hline Seismic & $\begin{array}{l}\text { Shear damage near } \\
\text { base of wall, some } \\
\text { dome cracking }\end{array}$ & $\begin{array}{l}.8 \mathrm{~g} \text { for DSTs } \\
.6 \mathrm{~g} \text { for SSTs } \\
\text { (no dome collapse } \\
\text { for }<1.5 \mathrm{~g} \text { ) }\end{array}$ & $\begin{array}{l}0 \text { for DSTs to minimal } \\
\text { for SSTs }\end{array}$ \\
\hline Organic nitrate burn & $\begin{array}{l}\text { Potential loss of } \\
\text { structural integrity }\end{array}$ & Not determined & Indeterminate \\
\hline
\end{tabular}

The panel concluded that the release quantity is most sensitive to analysis inputs and assumptions including the release scenario, accident scenario prediction (including tank failure mode), accident initiator identification and frequency, and transport. The panel also found that the most sensitive factors influencing the release-transport calculations are tank failure mode, assumptions regarding the quantity of reactive materials, release scenarios, and assumptions regarding the accident sequences.

Be aware of the following cautions on the use of the numbers/estimates presented in this report:

- The conclusions are applicable only to failure analysis/limits. 


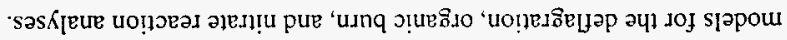

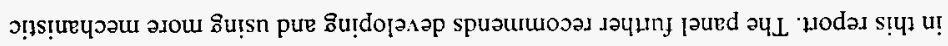
pə!!!

('sa!!!!

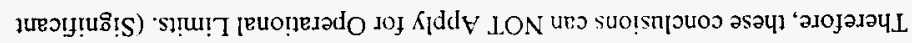

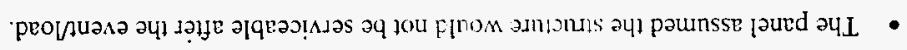

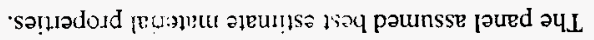

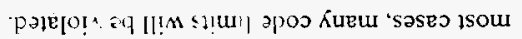

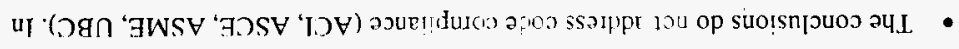

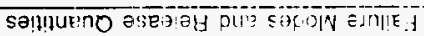

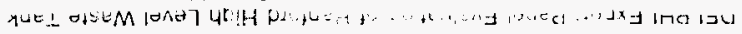

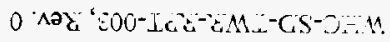




\section{WHC-SD-TWR-RPT-003, Rev. 0}

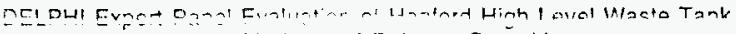

Failure Modes and Release Quãntities

\section{Contents}

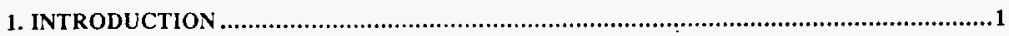

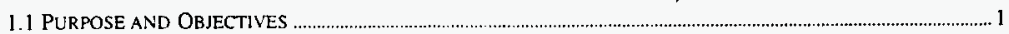

1.2 STATEMENT OF THE PROBLEM

1.3 METHOD

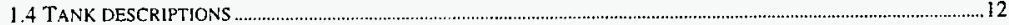

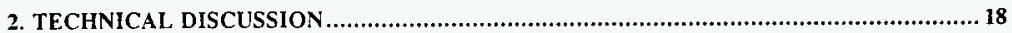

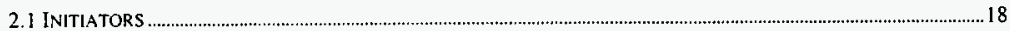

2.2 SENSITIVITIES AND CONFIDENCE

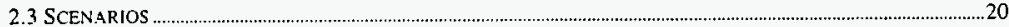

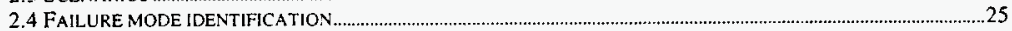

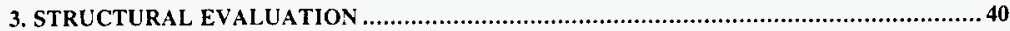

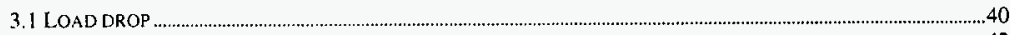

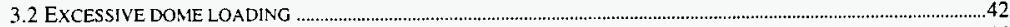

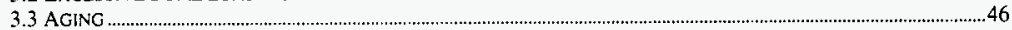

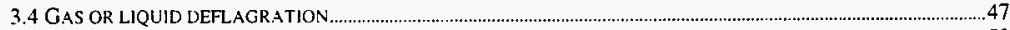

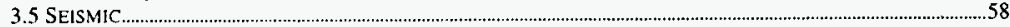

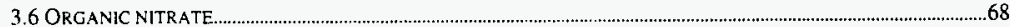

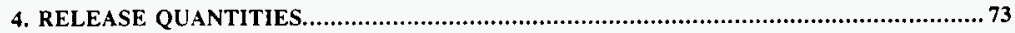

4.1 DELPHI QUESTIONS RELEASE QUANTITIES

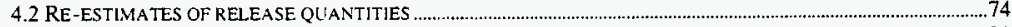

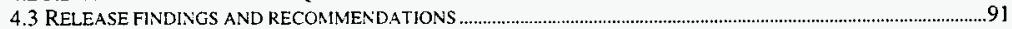

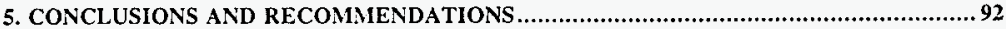

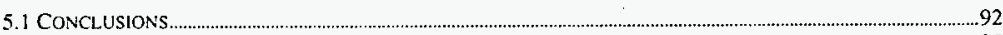

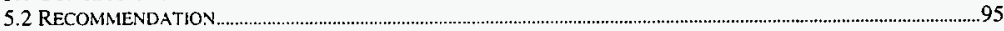

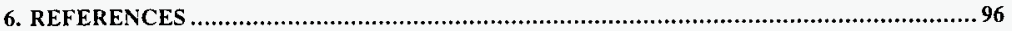




\section{Introduction}

\subsection{Purpose and Objectives}

The initial purpose of this Delphi analysis is to provide a release quantity for the TWRS Safety Analysis. This document is a supporting technical document for the FSAR. WHC chartered the Delphi expert panel to resolve an apparent discrepancy in the quantity of waste potentially released in the unlikely event of a catastrophic failure of a Hanford high level waste tank. Estimates performed by Las Alamos National Laboratory ${ }^{1}$ (LANL) estimated in excess of $100 \mathrm{~kg}$ of high level waste released to the air above a tank. Earlier estimates by $\mathrm{WHC}^{2}$ calculated only 7 (about $10 \mathrm{~kg}$ ) of waste released for air transport.

The panel agreed on a hierarchy of purpose to ensure that the panel focus remained at a high enough level to provide meaningful input to the Safety analysis. The panel accepted the result of the first round of Delphi questions, which ranked the four highest purposes of the Delphi panel effort (in descending order) as:

- Protect the public,

- Protect the workers,

- Operate the Hanford tanks safely, and

- Provide the basis for safety controls.

It is necessary for a panel such as the Delphi panel to clarify the high level purposes of their work so they do not become trapped into solving a symptom of a broader problem. Nadler and Hibano ${ }^{3}$ state, "Focusing on purposes helps strip away nonessential aspects to avoid working on the wrong problem... Thinking purposes is an important defense against the analysis-first and technology traps." This led to an entirely different outcome than would have come from redoing analyses assuming dome collapse.

In this work, focusing on these high level objectives was likely the primary reason the panel was able to quickly reach consensus on the need for a revised problem definition. 
Rather than focusing on, "the quantity of waste released in...dome collapse," the panel reevaluated tank failure scenarios to support these high level purposes.

Specific objectives established to support the purpose of the Delphi panel investigation are:

1. Assess important accident initiators,

2. Review applicable scenarios,

3. Evaluate tank failure modes, and

4. Estimate sensitivities and release quantity.

\subsection{Statement of the problem}

\subsubsection{Problem specification}

Table 1 presents a specification of the problem considered by the Delphi expert panel. The table identifies the specifications with terminology from the Kepner-Tregoe ${ }^{4}$ problem solving process. 'IS' identifies the parts of the problem addressed by the panel. 'IS NOT' provides a boundary for the problem.

Based on evaluation of the information needed to satisfy the high level purposes, the Delphi panel established its own problem statement as, "Identify the failure modes, failure limits, and release quantities for TWRS Safety analysis." The original problem statement was, "Identify and justify the air release quantity expected from the hypothetical collapse of the dome of a Hanford high level waste tank." The panel was unable to find evidence for the assumption of dome collapse for the scenarios posed, and thus had to develop this more expansive problem statement.

WHC Safety analysis personnel specified ${ }^{56}$ accident initiators for the Delphi panel to work with. These initiators include:

- Tank structure aging, 
- Excessive waste temperatue,

- Internal vacuum,

- Intemal pressúrization,

- Load drops onto soil or pit floors, and

- External pressure (local. c.g. large crane, or overall, e.g. excess soil depth).

In addition, the panel looked at seismic loading because this was known to be a potential key contributor to the overall risk from the Hanford tanks ${ }^{7}$, and is often a key risk contributor for nuclear facilities.

\subsubsection{Relation to overall analysis}

The Delphi panel analysis is a small part of an extensive and intensive evaluation of the safety of operating the Hanford high level waste tanks. The Delphi panel results are intended to guide future qualitative and quantitative analysis efforts, which will culminate in the TWRS FSAR and supporting authorization basis documents.

The Delphi panel intends that analysts use these results as guidance to structure and perform the detailed Safety analysis. The experience of the participants and the substantial quantity of quantitative analysis considered by the experts provides confidence that the qualitative conclusions of this analysis are correct. The time frame and data accessibility during the effort were not structured to ensure accurate quantitative results. Therefore, the recommendations of this work must be supported by additional quantitative analysis. Estimates of uncertainty in the quantitative conclusions are provided to illustrate confidence in the qualitative conclusions.

$\mathrm{Be}$ aware of the following cautions on the use of any structural numbers/estimates:

- The conclusions are applicable only to failure analysis/limits.

- The conclusions do not address code compliance (ACI, ASCE, ASME, UBC). In most cases, many code limits will be violated. 
- The panel assumed best estimate material properties. The piule issunked the structure would not be serviceable after the event/load.

Therefore, these conclusions can NOT Apply for Operational Limits. (Significant permanent damage would compromise operational load capabilities.)

Table 1: Delphi panel problem specification defines problem scope.

\begin{tabular}{|c|c|c|}
\hline Specification Topic & is & Is-Not \\
\hline What & $\begin{array}{l}\text { Hanford SSTS and DSTS } \\
\text { Accidents \& } \\
\text { Natural phenomena } \\
\text { Radioactive release }\end{array}$ & $\begin{array}{l}\text { Other Hanford tanks } \\
\text { Tanks at other sites } \\
\text { New tanks } \\
\text { Transfers } \\
\text { Other TWRS facilities } \\
\text { Sabotage } \\
\text { Other hazardous material release }\end{array}$ \\
\hline Where & $\begin{array}{l}\text { Hanford } 200 \text { area } \\
\text { Air release } \\
\text { Unfiltered release }\end{array}$ & $\begin{array}{l}\text { Other Hantord locations } \\
\text { Other DOE sites } \\
\text { Ground or sub-surface release } \\
\text { Filtered release }\end{array}$ \\
\hline When & $\begin{array}{l}\text { Present and future } 20 \text { years } \\
\text { During storage and stabilization } \\
\text { activities }\end{array}$ & $\begin{array}{l}\text { Past events } \\
\text { During remediation activities } \\
\text { After tank remediation }\end{array}$ \\
\hline Why & $\begin{array}{l}\text { Store waste function safety limits } \\
\text { and LCOs }\end{array}$ & $\begin{array}{l}\text { Store waste functional normal } \\
\text { operations limits } \\
\text { Remediation function activities }\end{array}$ \\
\hline Who & $\begin{array}{l}\text { DOE } \\
\text { DOE contractor } \\
\text { Public } \\
\text { Co-located worker }\end{array}$ & $\begin{array}{l}\text { Other federal agencies } \\
\text { Other private firms } \\
\text { Facility worker }\end{array}$ \\
\hline How & $\begin{array}{l}\text { Accidents caused by anticipated, } \\
\text { unlikely, and extremely unlikely } \\
\text { initiators }\end{array}$ & $\begin{array}{l}\text { Accidents caused by beyond } \\
\text { extremely unlikely initiators } \\
\text { Normal operating releases }\end{array}$ \\
\hline
\end{tabular}


$w-c-s D-w 2-2 \%-203$, sev 0

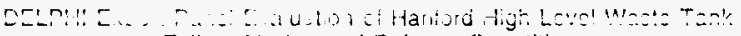

\subsubsection{Why Delphi?}

The Delphi method was selected 10 address this problem because-it is:

- Unique,

- Complex (i.e., involves more than one discipline),

- Technically difficult,

- Important, and

- Not fully resolvable by quantitative methods.

These characteristics identify problems that need the input from a variety of experts.

WHC is producing an FSAR for the TWRS Manage Waste function which requires the selection of a method for the deterministic Safety analysis. Two available analyses for the consequences of 'Dome Collapse' that differed widely in predicted outcome, and needed to select. One of the methods was yielding very high calculated radiation doses. The problem is to come to a consensus analysis that reviewers of the Safety analysis would approve, and that would serve the operational safety needs of Hanford. This is a unique problem.

Most successful problem analysts view the Delphi method as a strong contributor to resolving complex problems. Ideas of a wide range of experts help prevent some of the problems individuals or unstructured panel processes fall prey to, such as 'group think.'

Often, analysts quickly start very detailed analytical modes, when the problem specification is still highly uncertain. They may feel that methods such as Delphi are, "a method of last resort in dealing with extremely complex problems for which there are no adequate models." 8

Prediction of phenomena such as dome collapse are not completely resolvable by quantitative methods. The panel is addressing the differences between two prediction models. While such models can be very precise (that is, given the same input they produce the same output), they are not necessarily accurate. Very precise and detailed analysis of the 


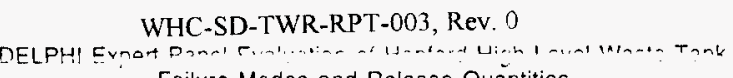

Failure Modes and Release Quăntities

wrong problem does not improve safety. Sometimes, the very precision of sophisticated computer models causes weakness in the safety process, as analysts miss or insufficiently analyze whole regimes of behavior because they didn't consider them up front.

The most relevant example of this is in nuclear reactor safety, an area of expertise of many of the panel members. Prior to the Three Mile Island Accident, very sophisticated accident models had been developed to analyze bounding accidents (large pipe breaks) in nuclear reactors, even though simpler, structured analyses (WASH-1400) had indicated that the more likely cause of harm to the public was another type of accident (The small break loss of coolant accident). The more likely accidents were not properly analyzed nor protected adequately because most of the research and analysis effort was directed at improving the precision of the unlikely (but conceptually more severe) large pipe break accident.

Successful problem resolutions support the advantages of starting with effective, structured group processes. Nadler and Hibano ${ }^{9}$ studied the characteristics of successful problem solvers, and identified seven principles that lead to successful solutions. The principles are:

1. Uniqueness: Every problem is unique, and the solution should recognize and focus on the unique problem aspects.

2. Purposes: Focus on the purpose for the solution leads to superior solutions. Initial problem statements usually cause panels to solve the wrong problem, and immediately dive into analysis of the wrong problem.

3. Solution-After-Next: A superior solution must consider the alternatives likely to be examined the next time the problem is addressed.

4. Systems: Like an iceberg, seven-tenths of most problems are beneath the surface.

5. Limited Information Collection: Only acquire data necessary to make decisions that provide the solutions needed. 
WHC-SD-TWR-RPT-003, Rev. 0

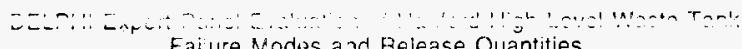

Failure Modes and Release Quantities

6. People Design: Superior solutions address the needs of all stakeholders.

7. Betterment Timeline: Rome wasn't built in a day. Superior solutions plan implementation in chunks that are realistic to accomplish.

This panel's process specifically addressed principles $1,2,4,5$, and 6 . This is the reason the panel started out by addressing the purposes. The panel intends that the ultimate use of the work will use all of the principles.

\subsection{Method}

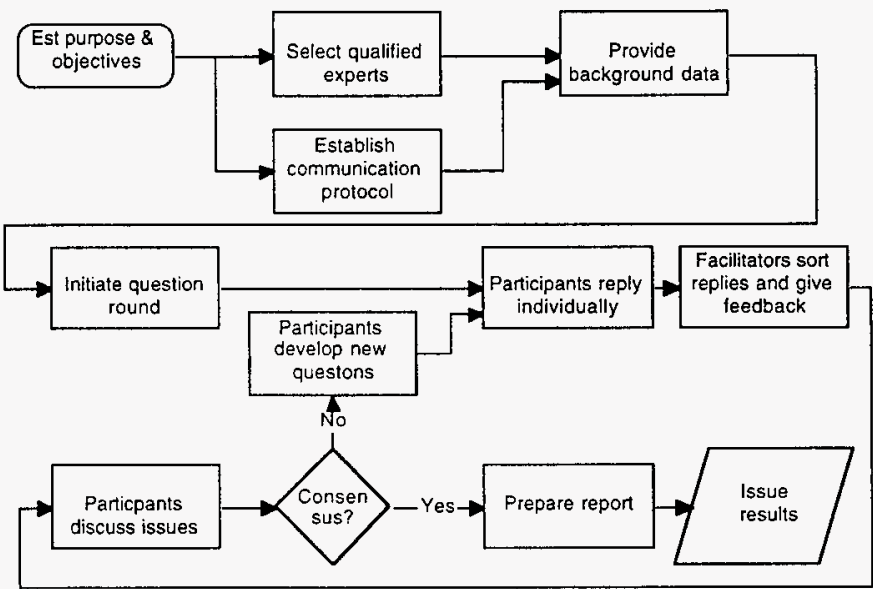

Figure 1: Delphi process uses multiple answer rounds to elicit consensus judgment.

\subsubsection{Method description}

The Delphi process structure elicits expert opinion in a way that eliminates many of the problems of group interactions. 
Figure 1 illustrates a typical Delphi process in which rounds of questions are sent out to experts. A steering group analyzes the results of each round, and sends out subsequent rounds of questions until the problem sand answers are narrowed down to achieve a solution. The solution may or may not result in consensus. Analysts usually present the results statistically.

Due to a relatively short time frame, the panel elected to use a meeting process to elicit the judgments. The panel provided each expert initial data and an initial round of questions. The panel planned to modify subsequent rounds of questions in the meeting, and allow time for free form panel discussion before the individuals completed the next round of questions.

The panel split into two sub-panels because the technical areas involved two specific areas of expertise: (1) structural analysis and (2) release and transport mechanisms. This approach followed a method used by the Nuclear Regulatory Commission for severe accident research. ${ }^{10}$ The two panels were brought together periodically to exchange views.

The Delphi process makes use of questions. Design of question is a potential cause of bias and error in panel results. Care was taken to structure questions used in this process to avoid bias." For example, the panel used both ranking and open ended questions. In all questions, the panel invited 'write-in' responses. The panel deliberately avoided listing things in the order they thought important.

Following the first two planned Delphi rounds, the panel assessed progress and plans for the remainder of the session. Based on the decisions made up to that point, the panel decided to supplement the basic Delphi process with additional controlled process steps. Figure 2 illustrates the altemate process the panel used to complete the activity. 

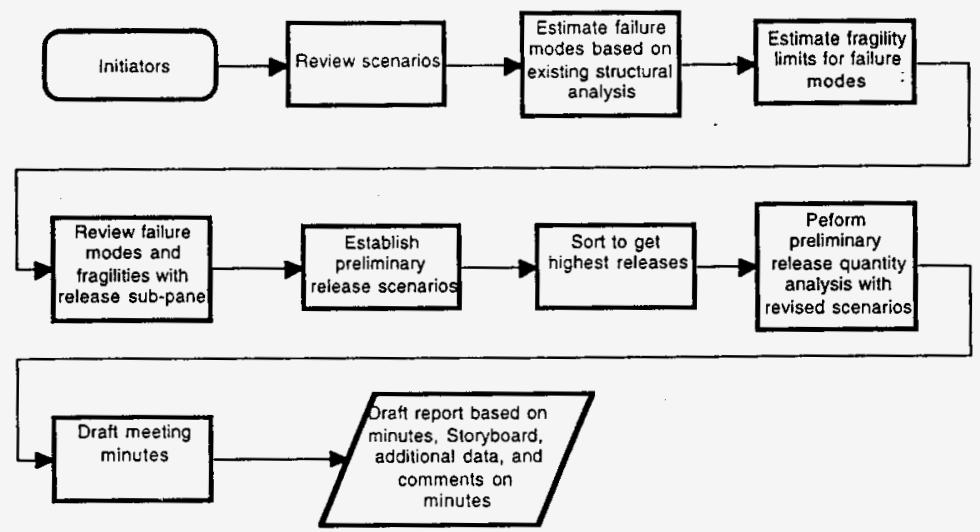

Figure 2: The Delphi panel supplemented the Delphi process with additional controlled process steps to achieve consensus on scenarios, failure modes and release quantities. 


\subsubsection{Expert qualifications}

Qualified experts participated in the Delphi panel. Figures 3 through 5 illustrate the overall panel qualifications in terms of education and experience. Figure 5 relates the panel members 'experience to the specific topical areas the panel addressed. The appendix provides more detailed summary resumes of the panel members.

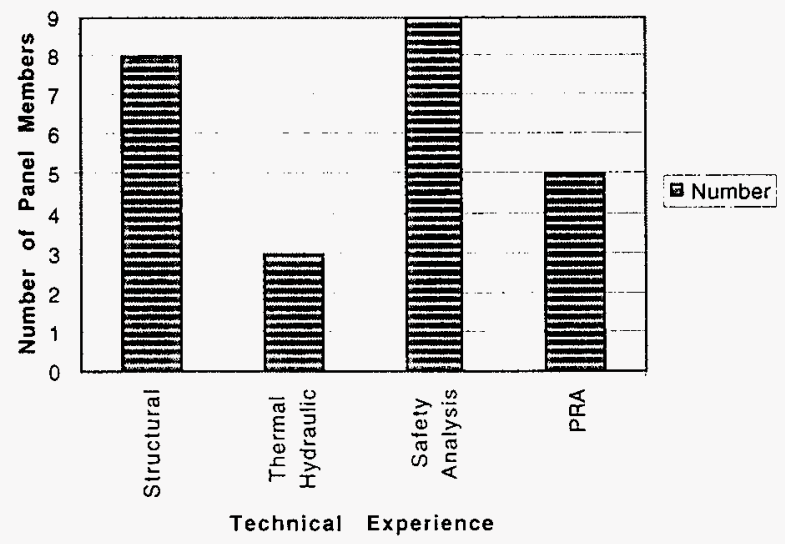

Figure 3: The Delphi expert panel members are well educated in the technical skills necessary for the assessment. 


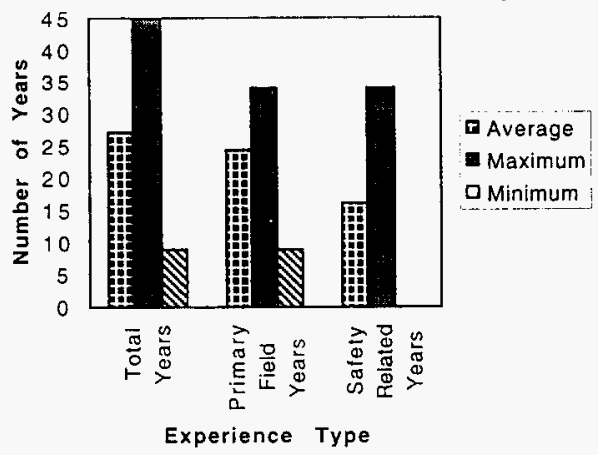

Figure 4: The Delphi panel members demonstrate extensive overall engineering and science experience, mostly directly related to subject area.

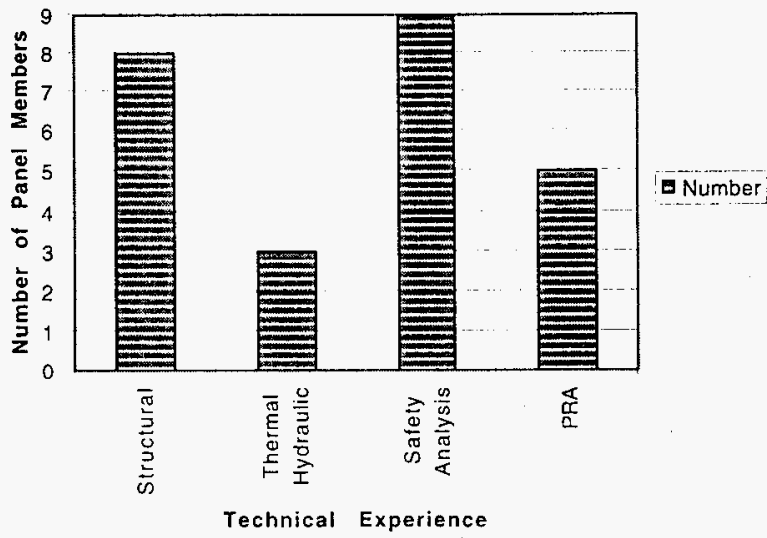

Figure 5: Panel members expertise covers the areas important to the TWRS tank dome collapse assessment. 
WHC-SD-TWR-RPT-003, Rev. 0

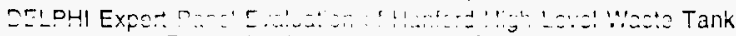

Failure Modes a ro Release Quantities

\subsection{Tank descriptions}

The Hanford Site stored high level nuclear wiste in two primary types of tanks. Figure 6 illustrates the most common type of Single-Shell Tank (SST). Figure 6 illustrates the newer Double-Shell Tank (DST) design.

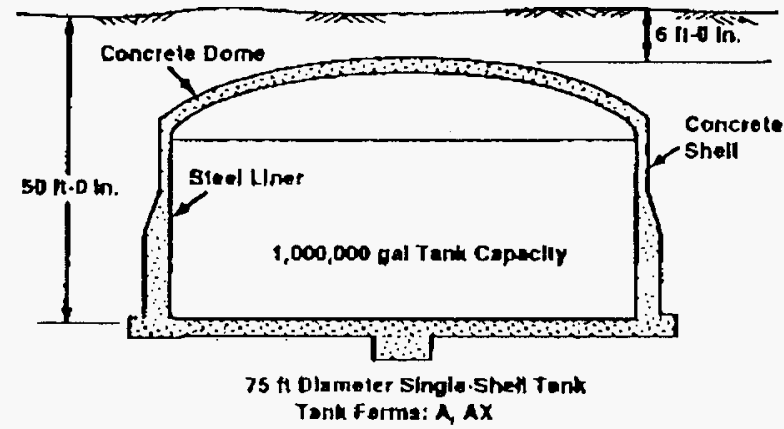

Figure 6: Hanford Single Shell tanks are thin reinforced concrete structures with a steel liner on the base and cylinder.

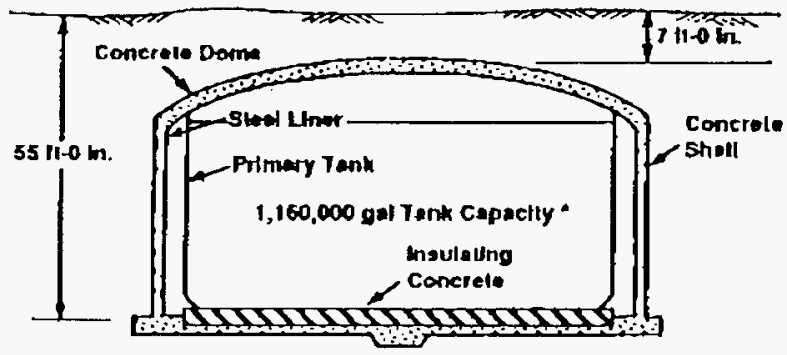

75 fl Dhameter Double-Shell Tank

Tank Farma: AM, AP, AW, sy

Figure 7: The Hanford Double Shell Tanks have two steel liners, and include lining of the dome. 
The 177 waste storage tanks are located in 18 separate tank farms at both 200 East Area and 200 West Area of which 12 tank farms are SSTs and 6 tank farms are DSTs. There are five basic designs for the underground waste storage tanks. Four of these designs are single shell; the fifth is a double shell tank design (Figure 7).

\subsubsection{Single-Shell Tanks}

The 149 SSTs were constructed between 1943 and 1964. There are two groups of SSTs as classified by their diameters. One hundred thirty-three of the SSTs have an internal diameter of 75 feet and sixteen SSTs have an internal diameter of 20 feet.

\section{SSTs with an internal diameter of 75 feet}

The construction of this group of SSTs are similar. The SSTs consist of a cylindrical wall, a basemat, and an elliptical dome. The tanks are constructed of reinforced concrete with a steel liner plate extending across the tank basemat and up the cylindrical wall. The steel liner provides the containment of the stored liquid waste. The height of the dome above the basemat varies from approximately 30 to $\mathbf{4 3}$ feet depending upon the design capacity of the individual tank The reinforced concrete tank is the load bearing structure and the liner plate is not considered as a structural element. The tanks are buried at various depths below grade. The nominal radjoactive liquid waste storage capacity of the tanks varies with the height of the cylindrical wall. There are three different storage capacities: 500,000 gallons, 750,000 gallons, and 1,000,000 gallons. The 500,000-gallon tanks have the shortest height and the 1,000,000-gallon tanks have the greatest height with the 750,000-gallon tanks being in-between the two.

\section{SSTs with an internal diameter of 20 feet}

There are 16 SSTs in this group. These tanks have a different configuration than the 75 feet diameter tanks. The 20 feet diameter tank is a vertical reinforced concrete cylinder surmounted with a 12-inches flat roof slab and rectangular pit. The overall depth of the 


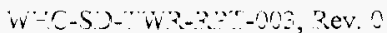

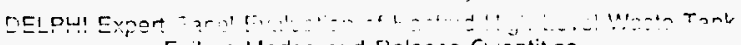

Failure Modes and Fielezse C! jantites

structure is 39 feet 7 inches. The $\tan x$ is Jin $\mathrm{d}$ with a $1 / 4$ inch thick steel plate. The tank has a 7 inches thick concrete base $; a b$. The 1.2 inshes thick cylindrical wall is supported on a circular concrete footing about 36 inches in diameter by 15 inches deep. There are a number of penetration risers located at the dome of the tiuks to allow access for instrumentation and equipment. Sizes of the risers range from $3 / 4$ in. to 42 in. The risers were fabricated from seamless carbon steel pipes except for those greater than 20 -in. in diameter which were rolled from steel plate and seam welded. The penetration risers are welded to the dome liner and encased in the concrete with penetration anchor studs. Some of the risers extend up through the soil to the surface of the grade while others extend up into the concrete pits above the dome. The pits are capped at grade with reinforced concrete cover blocks.

The SSTs are grouped in twelve tank farms. The designation of these farms are: $A, A X$, B, BX, BY, C, S, SX, T, TX, TY, and U.

\subsubsection{Double-Shell Tanks}

There are twenty eight DSTs located in six separate tank farms. Four of these tanks have a design capacity of 1,000,000-gallons. The remaining twenty four tanks have a design capacity of 1,160,000-gallons. All are referred to as having a nominal storage capacity of 1,000,000-gallons. The DSTs have fewer geometric and material differences than the SSTs. In general, the DST designs are all similar. Structurally, they are identical within any single tank farm grouping. Between the farms, the tank designs are structurally similar with some variations in concrete and rebar strength, rebar arrangement in the haunch region, and some variation in the basemat foundation design. The DSTs are 83 feet in external diameter, 50 feet high, consisting of a reinforced concrete secondary tank with an attached secondary steel liner encasing an integral primary steel tank. The secondary concrete tank is of cylindrical in shape with a shallow dome type roof.

The secondary steel liner is attached to the inner cylindrical wall and haunch region of the secondary concrete tank up to a point of tangency with the primary dome and flat bottom plate rests on the basemat. The primary tank is an integral cylindrical tank with an 


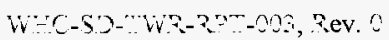

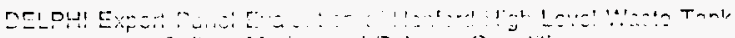

F ailure Mocle: and Relase Quantities

ellipsoidal head attached to the inner surface $c$ the concrete dome and a flat bottom rests on an 8-in. thick layer of refractory insulating concrete which separates the primary tank and secondary tank liner plate. There is a nominal 30 in. annulus between the primary tank cylindrical wall and steel lined reinforced concrete secondary tank cylindrical wall. The annulus contains systems for leak detection and ventilation/cooling. The primary steel tank provides containment for the stored liquid radioactive waste. The secondary steel liner and concrete tank serves as a redundant leakage barrier.

The DSTs are grouped in six tank farms. The designation of these farms are AN, AP, $\mathrm{AW}, \mathrm{AY}, \mathrm{AZ}$, and $\mathrm{SY}$.

\subsubsection{Penetrations and Risers of Single-Shell Tanks and Double-Shell Tanks}

There are a number of penetration risers located at the dome of the tanks to allow access for instrumentation and equipment. Sizes of the risers range from $3 / 4$-in. to 42 in. The risers were fabricated from seamless carbon steel pipes except for those greater than 20 -in. in diameter which were rolled from steel plate and seam welded. The penetration risers are welded to the dome liner and encased in the concrete with penetration anchor studs. Some of the risers extend up through the soil to the grade while others extend up into the concrete pits above the dome. The pits, not structurally connected to the dome except through the riser interface, are capped at grade with reinforced concrete cover blocks.

\subsubsection{Historical Information}

\section{Single-Shell Tanks}

The 149 SSTs were constructed between 1943 and 1964 with a design service life of 20 years.

The 55,000-gallon SSTs are located in Tank Farms B, C, T, and U. These tanks were constructed in 1943 and 1944. They are all identical. 
There are five SST tank farms ( B, BX, C, T, and U farms) containing 500,000-gallon tanks. Tanks in B, C, T, and U Tank Farms were constructed from the same drawings during $19+3$ and 19+4. Tanhs in BX Fank Farm was constructed in $1946-1947$. All these tanks have the same geometry with insignificant differences in number and size of reinforcement.

There are four SST tank farms (BY, S, TX, and TY) having tanks with a capacity of 750,000-gallor.s. These tank farms were constructed from 1947 through 1952 and are all identical.

There are three SST tank farms (A, AX, and SX) having tanks with a capacity of 1,000,000-gallons. The A and SX Tank Farms were constructed during the years of 1953 - 1955 and the AX Tank Farm ten years later in 1963 - 1964. The newer AX Tank Farm tanks have several design features different from the tank designs of the tanks in $A$ and $S X$ Tank Farms in that the dome radius is larger, the concrete strength is greater, and the steel liner is radiused at the junction of the shell-to-foundation.

All SSTs were removed from service on or before November 21, 1980. A total of 106 of the SSTs have been interim isolated and interim stabilized. Of the remaining tanks, 44 are partially interim isolated, and 14 tanks are partial interim isolated or interim stabilized.

\section{Double-Shell Tanks}

The twenty -eight DSTs were constructed between 1968 and 1986. Four of DSTs were designated as Aging Waste Facility tanks. Aging waste (neutralized current acid waste, NCAW) is defined as high level, first cycle solvent extraction waste from the Plutonium Uranium Extraction Facility (PUREX). These tanks have a nominal design waste storage capacity of 1,000,000-gallons each (operational limit is 980,000 -gallons). Two of the Aging Waste tanks located in AY Tank Farm were constructed in 1968 - 1970 with a service life of 40 years. The other two Aging Waste tanks located in the AZ Tank Farm were constructed in 1971 and 1977 with a service life of 20 years. 
Three DSTs in SY Tank Farro wers constuutec between 1974 - 1976, 6 DSTs in AW Tank Farm were constructed in 1978-1980, 7 ISSTs in AN Tank Farm were constructed

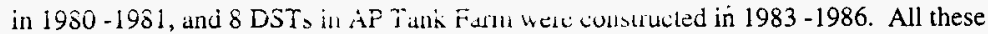
tanks have a nominal storage capacity of 1,160,000-gallons (operation limit is 1,140,000gallons per tank) and a service life of 50 years. 
WFC-SD-TWR-RPT-00S, Rev. 0

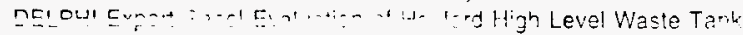

Falure Modes and Fizlesiso quantities

\section{Technical Discussion}

\subsection{Initiators}

The panel reached rapid consensus that the list of potential initiators was reasonable. As noted earlier, the panel elected to add seismic as an accident initiator. The panel also chose to change the grouping and definitions slightly to facilitate analysis. Table 2 shows the correlation between the categories used by the panel and those provided to the panel.

Table2: The panel sorted the accident initiators to facilitate analysis. The $x$ 's correlate the panel's sorting to the input provided by WHC.

\begin{tabular}{|l|l|l|l|l|l|l|}
\hline \multirow{2}{*}{$\begin{array}{l}\text { Categories assessed by } \\
\text { the panel }\end{array}$} & \multicolumn{5}{|c|}{ Initiators provided to the Delphi panel } \\
\cline { 2 - 7 } & & $\begin{array}{l}\text { Aging } \\
\text { excessiv } \\
\text { tempera- } \\
\text { ture }\end{array}$ & $\begin{array}{l}\text { Internal } \\
\text { vacuum }\end{array}$ & $\begin{array}{l}\text { Internal } \\
\text { pressur- } \\
\text { ization }\end{array}$ & $\begin{array}{l}\text { Load } \\
\text { drops }\end{array}$ & $\begin{array}{l}\text { Externat } \\
\text { pressure }\end{array}$ \\
\hline Load drop & & & & & $\mathbf{X}$ & \\
\hline Excessive dome loading & & & & & & $\mathbf{X}$ \\
\hline Aging & $\mathbf{X}$ & & & $\mathbf{X}$ & & \\
\hline Gas or liquid deflagration & & $\mathbf{X}$ & $\mathbf{X}$ & & & \\
\hline Seismic & & & & & & \\
\hline Organic nitrate & & $\mathbf{X}$ & & & & \\
\hline
\end{tabular}

\subsection{Sensitivities and confidence}

The panel answered questions to estimate the sensitivity of the release quantity to analysis inputs or assumptions. The panel members ranked the sensitivity of the release to the 
WHC-SD-TWR-??T-00S, Rev. 6

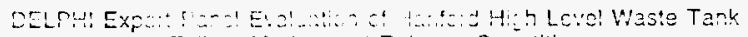

Failure Mode: and Releas Quantities

variables. The ranking results were, from most sensitive to least sensitive, as follows (with the most important ones shown in bold?:

1. Release scenario, model, and model assumptions.

2. Accident scenario prediction, including tank failure mode and fragility.

3. Accident initiator identification and frequency:

4. Transport, including the nature (form, particle size distributions), distance to onsite and offsite individual, exposed person assumptions.

Most of the panel felt highly confident in their estimates of these sensitivities.

The panel also ranked the variables that they felt the release quantity would be sensitive to in the release-transport calculations. The most sensitive, in terms of decreasing sensitivity, are:

\section{Tank failure mode.}

2. Assumptions determining quantity of reactive materials (e.g. flammable gas, nitrate waste). Inputs to tank models, e.g. quantity of flammable gas, reaction rate data.

3. Release scenario. Release Model/. Release model assumptions (e.g. entrainment model basis, size distribution or particles).

4. Assumptions regarding accident sequences. Tank loading accident models (e.g. gas deflagration model, nitrate waste deflagration model.)

Note that 2 and 3 ranked the same. All of the panel members felt moderately or highly confident in these sensitivity estimates.

Panel members ranked the sensitivity of release to the tank failure mode identification and fragility limits as much more sensitive than other structural variables listed for consideration. The other variables considered included: tank general design differences, tank aged condition, and tank structural model selection, assumptions, and inputs into the structural model, and tank materials of construction. Panel members all felt moderately or highly confident in their sensitivity rankings. 


\subsection{Scenarios}

\subsubsection{Previous Analysis Scenarios}

The panel focused on two previous calculations of release from the Hanford tanks. Westinghouse $e^{12}$ performed analysis as performed in support of an upgrade to the tank safety analysis. Westinghouse requested Los Alamos to perform an analysis for the deployment of the rotary mode drilling. The LANL Analysis ${ }^{13}$ is more recent. Both analyses end up assuming dome collapse, but result in widely different release results.

The releases in each of the analysis methods have common features. The principal components of the models are the following:

1. The initial loading of aerosol in the dome is important because it, or part of it, will be released in the tank failure. The initial loading is either due to vapor pressure of the liquid or solid waste form in the tank, or loading, or other work activities on the tank.

2. Entrainment of material into the dome region due to the accident initiator such as a deflagration. This material is important because some of this material is also released to the atmosphere when the tank fails due to the accident initiator. The accident initiator causes the tank to fail in some way. Both the Los Alamos and Westinghouse analyses assume that the failure is a collapse of the tank roof. The panel disagreed with this assumption and this report justifies that the tank failure mode will be cracks in the tank or at worst, the breaching of the tank with an opening at the top which resembles a parially open tin can.

3. Materials which are aerosolized from debris or roof material falling down into the tank from the accident initiator. In the Los Alamos and Westinghouse analyses, the roof of the tank is assumed to fall into the 


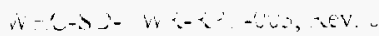

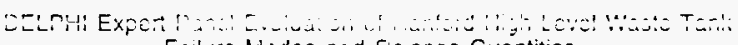

Fall de Modes and Fie ease Cuantities

waste and to aerosolize the naterial due to impact. Both Los Alamos and Westinghouse ate very conservative in the respirable amount that they assume is released to the atmosphere. In the panel estimate, a much more realistic, but still clearly consersative amount is estimated to be released to the atmosphere.

4. A release to the atmosphere which occurs over a long time due to continual entrainment of material by the passing of air over the tank opening (Bernoulli's effect). This contribution is small and in any case can be quickly terminated with installation of a cover over the tank.

Each of these steps are modeled with very conservative analyses by Los Alamos and Westinghouse. Item 3 is by far the biggest contributor in these analyses and the others may be neglected in comparison to it. The assumptions used in these analyses are often contradictory in order to add layers of conservatism to the analysis. For example, the both Los Alamos and Westinghouse assume that respirable size material is made by the roof when it falls in and that this material is entrained in air flowing over the tank even though a height difference of at least 30 feet must be overcome to get to ground level. It would take a high velocity to entrain this material, yet a low velocity is used to estimate the dose that an individual receives in order to maximize the calculated dose.

In this section, both the Los Alamos and Westinghouse analyses are briefly described. This is followed by the panel model and its results.

\section{Los Alamos Previous Analysis Scenarios}

The Los Alamos Analysis ${ }^{14}$ of the first three mechanisms described above are discussed in this section.

Initial Dome Loading and HEPA Filter Loading 


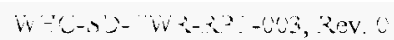

factor between the amount of respirable material that is generated and the amount of this material which would make it around the rcof szctions falling into the waste to generate the respirable material, the amount of respirable material which receives enough material to become airborne in the dome, and the amount of material which would make it out of the tank to be entrained in the air.

\section{Total Los Alamos Release}

Thus, the total release estimated by Los Alamos from the above three steps is

$$
\text { Total Release }=1.0+2.8+100 \mathrm{~kg}=104 \mathrm{~kg}
$$

\section{Westinghouse Previous Accident Scenarios}

Westinghouse's analysis ${ }^{15}$ for the dome collapse accident assumes that the dome caves in due to excessive weight. No contribution is estimated for the additional amount that deflagration would put in the dome atmosphere.

\section{Initial Dome Loading}

The initial dome loading is calculated by a partition function multiplied by the dome volume. This resulted in a value of 0.0125 liters of aerosol. Assuming a density of $1 \mathrm{~g} / \mathrm{cc}$, the weight is $0.0125 \mathrm{~kg}$.

\section{Material Release During Dome Collapse}

Westinghouse references a study of crushing of blocks of various materials by dropping weights on them. The potential energy of the weights dropped on the materials per unit volume of the material was used as a parameter in scaling up the results to the Hanford high level waste tanks. The percentage of the material which was less than 10 microns was used as the criteria for respirable material generated. Of course, in the experiment, none of the matcrial went airborne because it was captured by the falling block and the material was 
not elastic. Westinghouse used the pottntial sncrgy of the falling roof of the tanks to estimate the amount of respirable material which would be produced from a dry salt cake. All of this respirable material was asst:med to be dispersed to the environment without regard to a mechanism. Oi cunis, ins nateriai would have to become airborne in the dome some way and travel up the thirty or forty fect to the surface before it could enter the atmosphere, and then it would have to be entrained.

The amount of entrained material is calculated by Westinghouse with this method is 7.0 liters. Assuming a density of material as $1 \mathrm{~g} / \mathrm{cc}$, the weight introduced into the atmosphere from this mechanism is $7.0 \mathrm{~kg}$. 


\section{Total Westinghouse Release}

Thus the total release is

$$
\text { Total Release }=0.012+7.0 \mathrm{~kg}=7.012 \mathrm{~kg}
$$

This release is much less than the $104 \mathrm{~kg}$ estimate of Los Alamos. It is more mechanistic than the Los Alamos approach but it is still extremely conservative for the reasons mentioned above.

The largest release in both models is from the impact of roof material on the waste material in the tank. Other releases need not even be considered when the contribution from this one effect is so large. The purpose of the model presented by the panel is to present a mechanistic model to estimate the release from all of these contributors but principally the release due to the impact of material falling onto the waste.

\subsubsection{Delphi Panel Scenario Resolutions}

The panel members did not question scenarios up to the time of tank failure. Based on alternative failure modes, the release scenarios following tank 'failure' were reconsidered. Overall, since the panel did not identify 'dome collapse' as a safety significant failure mode, release scenarios based on sudden or incoherent collapse of the entire dome are not considered viable.

\subsection{Failure mode identification}

\subsubsection{Hanford Tank Model Results}

The Delphi structural panel considered the results from an ultimate load test of a $1 / 10$ thscale model of a million-gallon (241-A tank farm) Hanford SST. The model was tested to failure under incrementally increasing static compressive loading simulating the soil overburden load supported by the dome ${ }^{16}$. The $1 / 10$ th-scale geometric model was 


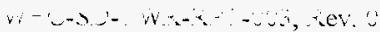

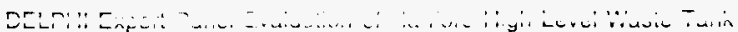

Failure Modes an: Release Zuantities

constructed from micro-concre and commercially available steel wire to simulate the prototype reinforcement bars. Evcry cffor w'as made in attempting to achieve the same material strength and modulus properties as specified in the prototype. The model was instrumented extensively with strain gages and deflection gages.

Deflections, crack patterns, distribution of service load, mode of failure, and ultimate capacity of a full-scale prototype structure can be accurately simulated in a micro-concrete scale-model test as has been convincingly demonstrated in the available literature of that time (ARH 1969). Prediction of the uitimate capacity of the tank structure through finiteelement analytical analysis using the scale-model test conditions have also indicated fairly good correlation with the test results as the ultimate load capacity is approached. However, although the location of failure is predicted, the finite-element analysis under predicted the ultimate capacity by about $25 \%$. (see Appendix C of WHC, 1993) ${ }^{17}$ The pictures below illustrate that the mode of failure was as the experts predicted for this type of loading. Vertical and horizontal cracks initiating at the wall-to-haunch construction joint extended down the wall, up into the haunch, and into the dome region with increasing load. The mode of failure was a simple combined bending and axial compression failure of the cylinder walls or "slabbing" as it is sometimes referred to, and was fairly uniform around the model.

Prior to the final static load test sequence the model was subjected to a $100^{\circ} \mathrm{F}$ through wall thermal gradient that induced extensive cracking. In particular, there was evidence of internal cracks parallel to the inside surface of the wall located at about the position of the inside reinforcement mat as observed from a core drill sample of the scale-model tank wall. Hence, internal cracking, not apparent from surface inspections, may have been rather prevalent as a result of the thermal test condition. 
W'C-SO- Wa-

Faitura Modes a y Ralecse Quántities

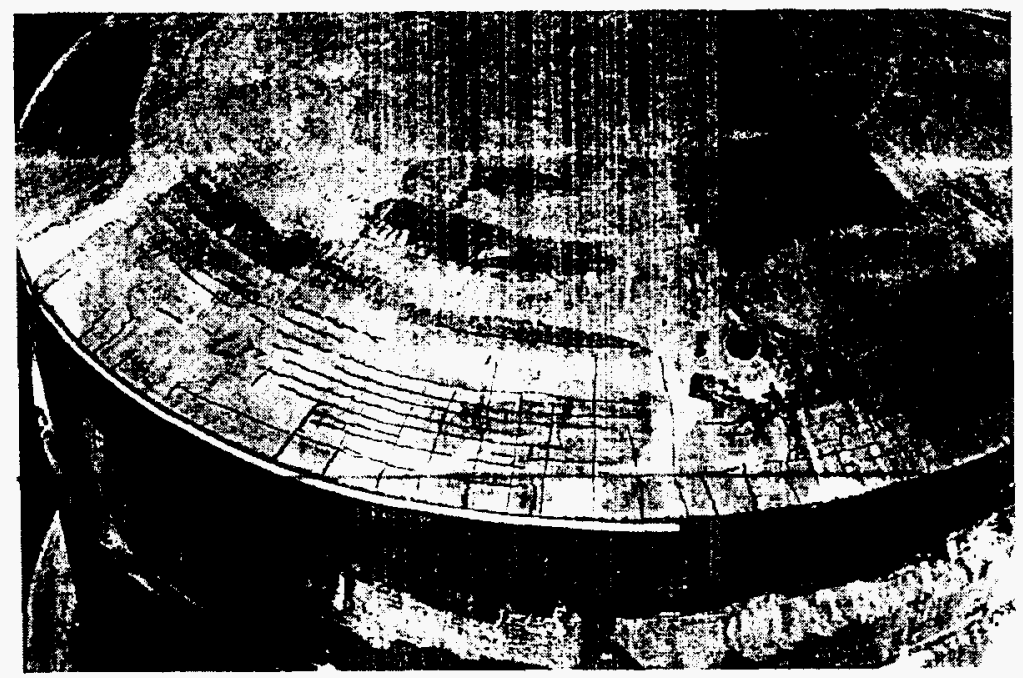

Figure 8: Photo of Hanford tank model load test result showing dome cracking

Although the load deflection curve had clearly become nonlinear as the ultimate failure load was approached. "the ultimate failure was sudden with little or no advanced warning" (ARH 1969). Post failure behavior of the tank Was not simulated in this test because the applied foad was relieved once the ultimate failure load was reached. At the ultimate load condition spalling was evident from both the inside and outside surfaces in the wall region adjacent to the haunch.

Because the test load applied to the dome was relieved upon reaching ultimate capacity the progression of the failure was not characterized. Hence. the results from this test cannot be used to establish the extent of spalling or breakup of the dome in the post fitilure regime. 


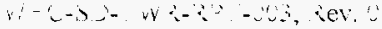

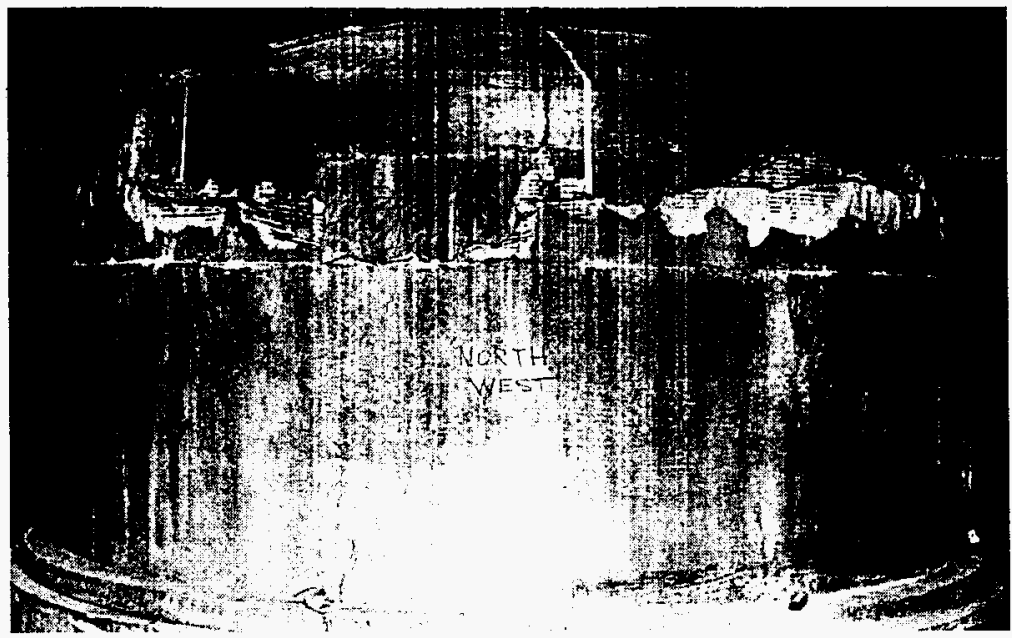

Figure 9: Photo of Hanford tank model load test result shows failure in side wall from excessive loading. Note the dome did not 'collapse.'

On the basis of the $1 / 10$ th scale-model test defined failure load of $5.400 \mathrm{Jbt} / \mathrm{ft}^{2}$ (includes dead weight for concretc dome) and current operating safety limits for soil overburden on SSTs (10 feet with a soil specific weight of $115 \mathrm{lbf} / \mathrm{ft}^{2}$ and an approximate $188 \mathrm{lbf} / \mathrm{ft}^{2}$ to account for the dead weight of the concrete dome), the predicted factor of safety against collapse is approximately 4.0 [i.e.. $5.400 /(115 \times 10+188)=4.0]$ which would correspond to about 45 feet of soil at failure. However, this result does not account for the presence of any uniform (internal vapor pressure or external snow) or concentrated (heavy equipment and/or crane) live loads.

\subsubsection{World Failure Data}

The Delphi structural panel comsidered world failure data in their deliberations when coming to consensus on the structurat integrity and failure modes of the high level waste tanks for the beyond design baxis environmentat and accident loads. This data included experience data tatien firmm 3.3 eathquakes around the world on the performance of 
-IIJM KJOA op KI[Ensn

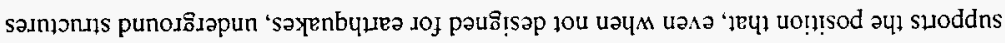

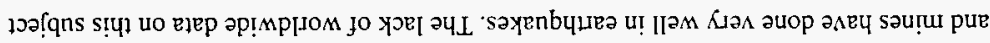

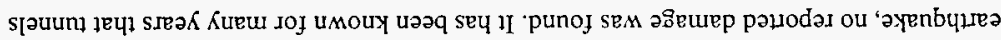

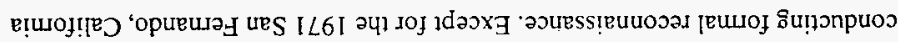

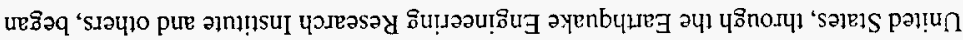

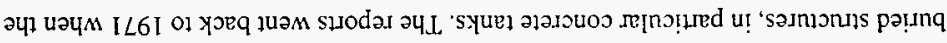

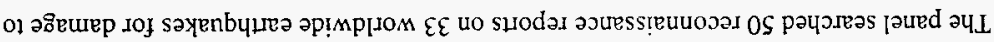

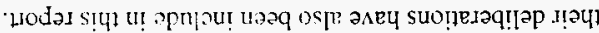

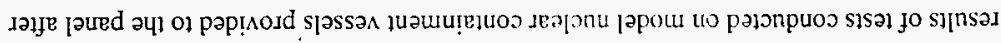

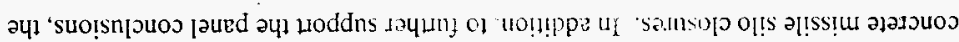

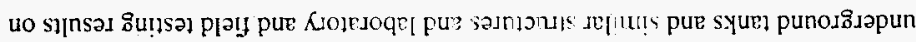




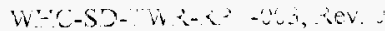

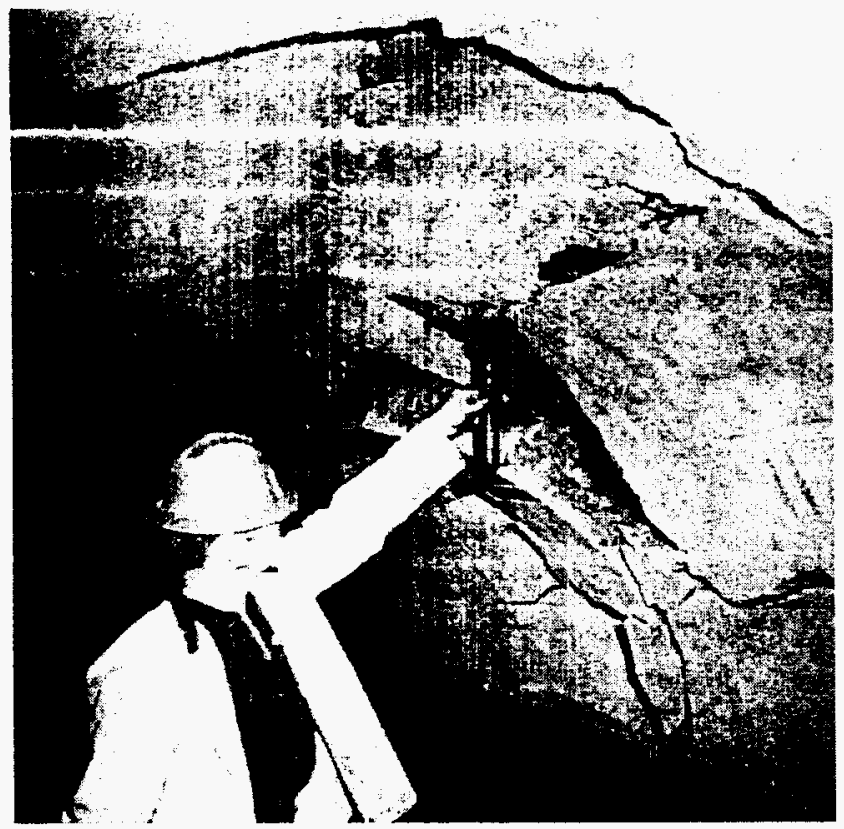

Figure 10: Worst case reinforced concrete underground structure failure. Note that the failure mode is deformation with cracks and concrete retention.

Figure 10 is the worst case of concrete structure fitilure the panel could find in the literature. Although the tunnel is severely deformed and cracked, spalling wats relatively minor and the structure held together physically, as with all obierved reinforced concrete structure failures.

The following paragraphs explain some specific fallues observed fiom the 1971 earthquake in San Fernando. CA. ${ }^{1 *}$

In the 1971 carthyutie thee concrete tank water storage reservers (Reservoirs No. 3 through 5) in the city of San Fernando experienced $0.25100 .5 \mathrm{~g}$ of horizontal acceleration and ahout half that in verticat accklatton. In ahdition, the reservoirs were 


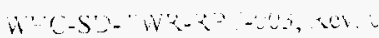

located with 0.25 to 0.5 mi es of the stirface upture and experienced general uplift of the ground several feet during the earthquake. Fortions of these tanks projected above the finished grade in that they were constricted on sloped ground, thus they were not fully buried.

Reservoir No. 3 was 50 feet in diameter and had a height of 12 feet (113 thousand gal capacity) with a wood roof. The water level at the time of the earthquake was 10 feet. The construction of Reservoir No. 3 predated 1962 and included no seismic design. Reservoir No. 3 was virtually undamaged.

Reservoir No. 4 was 78 feet in diameter and had a height of 31 feet ( 1 million gal capacity) with a flat reinforced concrete roof. The water level at the time of the earthquake was 29 feet. The backfill was within 10 feet of the top, thus. 19 feet of the tank was buried. The construction of Reservoir No. 4 was conducted in 1962 and included no seismic design. Reservoir No. 4 sustained damage only to the piping.

Reservoir No. 5 was 163 feet in diameter and had a height of 17 feet (2.4 million gal capacity) with a flat reinforced concrete roof. The water level at the time of the earthquake was 15 feet. The backfill was at the top of the tank on the uphill side and about 3 feet below the tank on the downhill side. The construction of Reservoir No. 5 was also conducted in 1962 and included no seismic design. Reservoir No. 5 suffered horizontal cracking in the lower portion of its wall on one side of the tank. As quoted in the reconnaissance report "The horizontal cracks in the lower portion of the walls of Reservoir No. 5 may have been the result of overturning moments created by the severe horizontal ground accelerations and uplift, which would tend to produce cyclic changes in the lateral support of the walls or sudden differentials in the pressure exerted on the reservoir base.

A fully buried concrete tank had just been built, but had not been filled with water. It was rectangular 520 by 500 feet, with a ceiling to floor height of 37 feet. The flat concrete roof, which was supported by interior columns, was being covered to a depth of 7 feet. At the time of the earthquake the soil depth was about 5 feet. It is estimated 


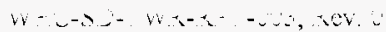

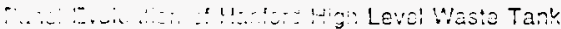 \\ Fail dre viodes ard Felease ouaritities}

D든ㅁ!: $\because \ldots$

that this reservoir experienced maximur horizontal accelerations of $0.4 \mathrm{~g}$. This force, when applied to the roof and fill cover, provided shear forces in the roof diaphragm of about 450 to $500 \mathrm{psi}$, clearly exceeding the shear strength of the concrete. Spalling and cracking of several floor slabs and construction joints occurred. Roof columns were damaged and the walls were breached in one or two locations. However, the reservoir did not collapse.

\section{Army Corps of Engineers Data}

The US Army Corps of Engineers performed tests of the response of concrete slabs to static and dynamic loading. ${ }^{19}$. They pressurized a variety of reinforced and unreinforced slabs from above. Although the unreinforced slabs would blow out the whole unsupported area, the photos below illustrate typical results with reinforced slabs. Figure 11 is typical of the failure mode with water pressurization, and figure 12 of the mode with air pressurization. These slabs failed at high pressures; i.e. around 1,000 psi.

Figure 11 is the worst expected failure mode for the tanks, unless there is a 'blow-out.' Figure 12 is the predicted 'can-opener' failure that would occur with an internal blowout. Note that in both of these cases substantial concrete adheres to the rebar, even with the case of a $1,000 \mathrm{psi}$ air blowdown. Local blowdown forces will be much less with the modest failure pressures predicted for the Hanford tanks. The Hanford tank failures would, of course, be inverted, further reducing the possibility of concrete loss. 


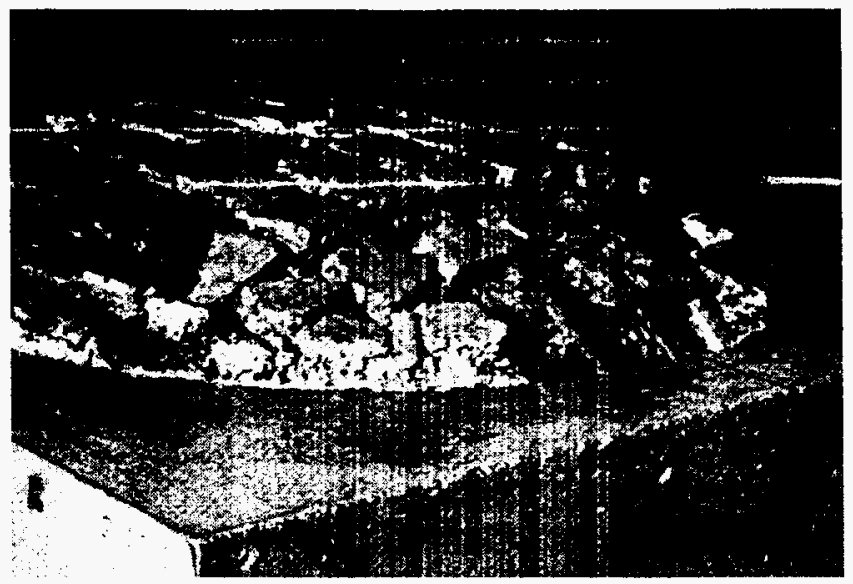

Figure 11: Reinforced concrete failure from over-pressurization with water. This is the cracked failure mode predicted by the expert panel. Note concrete retention.

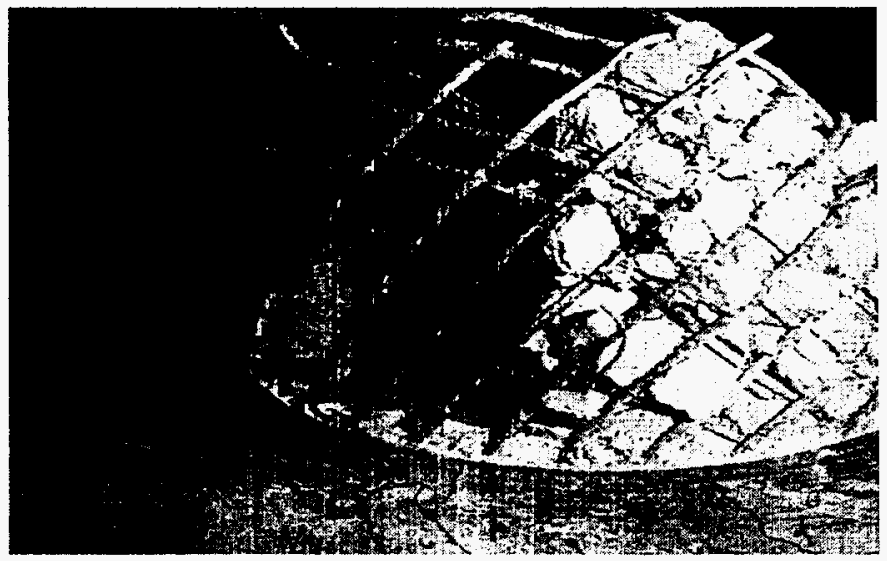

Figure 12: Reinforced concrete failure from over-pressurization with air. This is the 'canopener' failure mode predicted by the expert panel. Note concrete retention. 
Similar studies were conducted in the fiel $\pm^{2 !}$ using the detonation of 100 tons of TNT as the blast pressure source. The blast pressure subjected similar slabs to a dynamic loading of 900 psi with rise times of nme nillies and a duration of five millisec. For the same reinforced concrete slab construction as shown in Figure 10, only minor damage occurred. Minor damage was defined as: (1) no apparent permanent deformation at the center of the slab; (2) minor but well-formed crack patterns on the top and bottom surfaces of the slab; (3) no spalling of concrete on the bottom surface; and (4) the usability of the slab for the original intended purpose.

A second series of field test ${ }^{21}$ were conducted used to simulate a $1.5 \mathrm{Mt}$ nuclear burst by detonating $10,000 \mathrm{lbs}$ of pentaerythritol tetranitrate. The pressure experienced by a nearly identical slab as in Figures 10 and 11 was in excess of 6,000 psi with a rise time of 0.1 millisec and a duration of 150 millisec. The slab experienced damage very similar to that shown in Figure 11.

\section{Sandia Containment Failure Experiments}

Sandia National Laboratories completed testing of a 1:6-scale containment building for a light Water Reactor (LWR) in July $1987 .^{22}$ The containment building was made of reinforced concrete and had many of the features of full-size containments. The test program consisted of a Structural Integrity Test, an Integrated Leak Rate Test, and a concluding high overpressurization test of the structure which was carried to the limit of the nitrogen supply system.

The containment model was tested to investigate the behavior of containment structures subjected to pressure loading far beyond their design basis. The test results confirm and substantiate the overpressure failure behavior of the Hanford High Level Waste Tanks hypothesized in this study. Failures occurred near high stress areas and the failures were not catastrophic but instead were cracks in the walls which opened up enough to release the gas being feed into the containment. 
The containment model was buil: by ' 'nited Engizeers and Constructors to the American Society of Mechanical Engineers code standards with a design pressure of $46 \mathrm{psig}$. The 37-foot-tall model had an inside diameter of $22 \mathrm{ft}$ and many special features including:

2 personnel air locks,

2 equipment hatches and operable covers,

3 piping clusters,

2 spanel lines,

8 layers of primary reinforcing in the cylinder, and

a thin steel liner anchored to the concrete by headed studs.

The overall geometry of the containment was close but somewhat different than the shape of the Hanford tanks. It was a right-circular cylinder attached to the flat basemat and capped by a hemispherical dome.

Low-pressure testing, which consisted of a Structural Integrity Test and an Integrated Leak Rate Test was completed in early July 1987. These tests involved pressurization to 1.15 times design pressure for the first test and design pressure for the second test. The resultant cracks in the concrete were uniform in the cylinder with an average spacing of about $41 / 2$ in. Very few of the cracks exceed a width of 0.010 in. Very few cracks were detected in the dome region, and those present had widths well below 0.010 in.

High pressure testing of the containment was conducted in July 1987 by pressurizing the containment with nitrogen until leakage exceeded the capacity of the pressurization system. During high-pressure testing, the load was increased in steps ranging in size from 2 to 10 psi. After the containment was held at each increased pressure level of about half an hour, all transducers were remotely scanned, and the results were stored on a data acquisition computer. Before the pressure was increased to the next level, photographs were taken via computer control from nine fixed camera positions, and portions of the containment were video taped by 12 video cameras. 
High pressure testing ended after 32 hours. The containment model was pressurized to over three times its design pressure of $46 \mathrm{psig}$. At the peak pressure level of $145 \mathrm{psig}$, leakage exceeded $4000 \mathrm{scfm}$, which was the limit of the pressure source. This ended the tect.

The cracks which had developed during the low pressure testing became much wider (many were 1/8 in. wide) but few new cracks developed. Radial displacements at the cylinder mid-height were roughly $11 / 2$ to 2 inches, while typical strains in the hoop direction were between $11 / 2$ to $2 \%$. The peak liner strain recorded exceeded $8 \%$. One of the equipment hatch sleeves was deformed into an oval, which exposed one of the two gum-drop seals for a portion of its length. A dishing of the basemat was observed, which resulted in an average uplift of the outer edge of the basemat of about $3 / 8$ in.

Leakage from the containment model was quite small for most of the test, however, during the final few pressure steps, leakage grew rapidly. At $135 \mathrm{psig}$, a leak rate of about $8 \mathrm{scfm}$ was measured. This grew to $50 \mathrm{scfm}$ at the pressure level of $143 \mathrm{psig}$, and by the next pressure level, $145 \mathrm{psig}$, leakage grew to over $4000 \mathrm{scfm}$. The major source of leakage was a 22 in long tear in the liner. This major linear tear was next to the insert plate for a piping cluster used for the pass through of instrumentation wires.

Upon further investigation after the test, many other highly distressed areas were found in the liner. In five of these areas, tears existed that were about $1 / 2$ to $1 / 8$ in long. Each of these tears, including the major tear, was adjacent to a stud that attached the liner to the concrete. This result is consistent with the conjecture of this report that failures of the Hanford tanks would occur preferentially at high stress points.

Posttest evaluation revealed large strain concentrations near the penetration insert plates that were strongly influenced by the studs that anchored the liner to the reinforced concrete wall. In addition to the six tears, there were many areas that had visible signs of distress.

The penetrations, in general, were stiffer than the non-perturbed wall: the cylinder wall moved radically farther outward than the penetrations. The perimeter of the basemat lifted 
off the work mat about $3 / 8 \mathrm{in}$ at the peck ressure, however, only a small amount of uplift remained after the internat pressure was released. Very little plastic response was observed in the steel in the basemat or the donce of the containment.

In general, for the accident loads considered, results of the Sandia tests support the conclusion of the Delphi panel; that catastrophic failure of the tank will not occur. Instead, cracks will open in the wall to relieve pressure. The cracks are probably smaller than assumed in the Delphi panel release calculations, and less material will fall back into the tanks and therefore form less aerosol than assumed in the calculations. 


\section{CEGB 1:10 Scale Containm, t]ests}

Britain's Central Electricity (Generating Board (CEGB) commissioned the design, analysis, construction and testing of a prestressed concrete model representative of the Sizewell 'B' primary containment. ${ }^{23}$ The model represents a scaled version of the full size structure. The major dimensions are well represented and the strengths and stiffness of the elements were modeled as closely as possible. The 45 grade $5 \mathrm{~mm}$ aggregate model mix matched the expected strength of concrete in the full size structure and the ratio of tendon centers to section depth was retained by employing a one for one replacement of the $37 \times 15 \mathrm{~mm}$ diameter tendons by 8 and $12.9 \mathrm{~mm}$ diameter strands. The model had no steel liner.

The model was first subjected to a pressure cycle up to $0.0345 \mathrm{MPa}$ (10\% of design pressure) for general system checking, followed by three cycles to $0.4 \mathrm{MPa}$ to check elastic response. This regime closely resembles that adopted for the structural overpressure test for full-size PWR containment. The model then underwent a 24 hour test to evaluate creep. The final or ultimate load test involved raising the internal pressure steadily until the model suffered gross and inelastic deformation.

During the first elastic test, base displacements showed a departure from linearity and some hysteresis between 0.26 and $0.4 \mathrm{MPa}$ indicating progressive cracking of the unprestressed concrete. In later tests, although the base appeared softer than in the first test, the data was more linear. This improved linearity up to $0.4 \mathrm{MPa}$ showed stabilization of the initial cracking. Wall-base junction reinforcement gauges gave readings consistent with the reported base behavior.

In the wall-base junction area, bending stresses dominate and reinforcement arrangement is important. Reinforcement yield was shown in the base and at the wall/base junction between 0.5 to $0.68 \mathrm{MPa}$. In the barrel wall, the most significant strains at high pressure were those in the hoop direction. Onset of vertical cracking took place at about $0.55 \mathrm{MPa}$. In the vertical direction a similar pattern emerged. In both directions in the barrel wall, the stiffening effect of the buttresses was quite clear from the experimental results. 
Slight spalling of the concrete at the bottom of the buttress at 161 degrees indicated incipient crushing near the end of the test. Although not having reached failure conditions, some hoop tendons exceeded $1 \%$ strain and were clearly beyond their elastic range.

At pressures above about $0.75 \mathrm{MPa}$ the model suffered gross and inelastic distortion due to the formation of hinges in the base and wall base junction consequent upon the yielding of this reinforcement. The structure became unable to sustain increases in internal pressure at $0.77 \mathrm{Mpa}$, a value of 2.24 times design pressure.

The results of this testing again show the model adopted here for the Hanford tank failure mode is conservative. The failure is not catastrophic but instead cracks develop and grow in size until the leak rate exceeds the supply gas. No large size opening developed which would allow material to fall into the tanks and generate aerosol in the tanks. The spalled concrete is the only material which would probably fall into the waste to generate aerosol.

\subsubsection{World Failure Data Conclusions}

1. Well designed underground reinforced concrete tank structures can fail when experiencing excessive overloads by deformation and cracking. No experience data was found to support the position of wholesale collapse. To get wholesale collapse would require unlikely excessive loads combined with unique loading mechanisms such as adding another 30 feet of soil to the top of the tanks as postulated in the accident scenario described in Section 3.2..

2. Spalling can be associated with failure, especially in earthquakes, but the amount of concrete spalled is typically modest for well designed underground reinforced concrete tank structures, unless the loading reaches an order of magnitude higher than the design loads.

3. Areas of major failures are predictable by structural analysis, and often by simple inspection of the structure. 


\section{Structural evaluation}

This section summarizes the results of deliberations by the structural sub-panel. The experts discussed technical considerations and reached consensus on failure modes. Panel members accepted assignments to draft the material presented below. Panel members reviewed and concurred in the final report.

\subsection{Load drop}

\subsubsection{Load drop scenario}

Load drop is the impact on the soil above the tank or in the pump pit from dropping objects lifted above the surface by a crane or other lifting device. The analyses assume free-fall, and thus create a specific impact energy.

\subsubsection{Load drop technical basis}

The LANL mixer pump safety assessment ${ }^{24}$ considered an $11,340 \mathrm{~kg}(25,000 \mathrm{lb}$.) pump dropped from a height of $3 \mathrm{~m}$ onto (a) the top of a tank, (b) onto a riser, and (c) onto the pump pit floor. The actual weight of the pump is $9070 \mathrm{~kg}(20,000 \mathrm{lb}$.). The larger mixer pumps scheduled for Tank 101-AZ weigh 12,730 kg (28,000 lb.). Based on a pump weight of $11,340 \mathrm{~kg}(25,000 \mathrm{lb}$. $)$ a drop of the pump onto the pump pit floor from more than 2-3 $\mathrm{m}$ (e.g., about 200,000 ft-lb.) will fail the pump pit floor and most likely perforate the tank dome. A drop onto the tank from $3 \mathrm{~m}$ will just miss causing dome collapse based on the LANL mixer pump analyses. A drop from $3 \mathrm{~m}$ equates to an impact velocity of 7.7 $\mathrm{m} / \mathrm{s}$. 


\section{Single-Shell Tanks}

The structural sub-panel concluded in the two-day I)elphi meeting:

- Tunch thruguis wuald ocis

- Spalling of concrete inside the dome would occur

- Spalling out to a radius of 10 feet might occur

The Structural Panel concluded that a pump drop with an impact energy of $200,000 \mathrm{ft}-\mathrm{lb}$. striking the bare concrete of the dome with a thickness of 15 in. would perforate the dome. Concrete would spall adjacent to the impact point. The experts estimated that the extent of the spalling might extend to approximately $10 \mathrm{ft}$ diameter. If the pump dropped on the grade, the soil will act to spread the impact force to a much larger area of the tank dome and absorb much of the energy. The dome would not fail if the pump dropped on the soil above the tank from a height of $3 \mathrm{~m}$ because the soil would decelerate the mass and spread the load.

\section{Double-Shell Tanks}

The structural sub-panel concluded during the two-day meeting:

- Even if local dome failure occurs, the primary liner is ductile.

- Mass and height can be assumed which will punch through the primary liner.

The structural behavior of the DSTs due to pump drop load is similar to the SSTs, except the primary steel tank is ductile and large deflection of the steel tank is expected before perforation. This would result in less concrete debris falling in the waste below than the SSTs. 
W'- $(-5)-W ?-3,-003$, Rev. 0

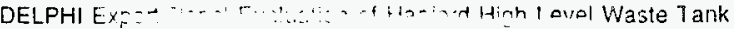

Fatlue Modes; and Fielease Quantities

\subsubsection{Load drop findings and recommendations}

1. The previous LANL analysis applies, clemonstrating the potential for perforation of the concrete dome in the pump pit due to a concentrated load drop with hinetic energy of $200,000 \mathrm{ft}-\mathrm{lbf}$.

2. The previous LANL analysis demonstrates that load drops of equal energy onto the soil would not perforate the tank.

In DSTs, deflection of the steel liner will limit concrete falling onto the waste, therefore limiting airborne activity in the tank free volume, and may preclude a new release path.

\subsection{Excessive dome loading}

\subsubsection{Excessive dome loading scenario}

Excessive dome loading is the static analysis of an increase in the uniform pressure on the dome. This may be due to an increase in soil density, increase in the quantity of soil, or placing of uniform distributed loads on the soil. Excessive dome loading also considers the possibility of a 'regional' distributed load; i.e. less than the full surface area of the top of the tank.

\subsubsection{Excessive dome loading technical basis}

\section{Uniform load}

The following conclusions were reached in the two-day structural sub-panel Delphi meeting:

- Over stress the upper wall.

- Haunch would fail in hoop tension. 
- It would require about $30 \mathrm{ft}$, of adititior al over surden to cause the failure.

Following the meeting, the following additional information was developed to substantiate

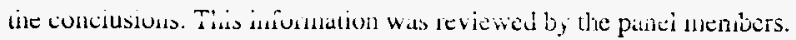

Current studies ${ }^{25}{ }^{26}$ suggest the DSTs can withstand a load of $7.2 * 10^{6} \mathrm{lb}$. (including a 50 ton concentrated load and $100 \mathrm{lb} . / \mathrm{ft}^{2}$ uniform load). The uniform load considers partial soil saturation due to snow melt or rain fall.

The DST and SST external loads (soil, concentrated load, uniform load) are quite similar. The tank diameters and dome curvature are also similar. The DSTs have a steel liner in the dome where the SSTs do not. The FSAR analysis will assume that initially the external loads result in peak stresses equal to code allowable for DSTs. For SSTs, the analysis assumes peak stresses are beyond code allowable but not at the point that failure would occur. From these conditions, the analysis will assume that an additional $1 \mathrm{ft}$ of gravel is added to the dome for contamination control.

The structural experts agreed, based on existing stress analysis and known tank failure modes, that the mode of failure would be hoop tensile failure of the haunch region or failure of the upper wall region of the concrete tank. It was felt that this type of failure would result in the dome failing and then "settling into" the waste in rather large (potentially one) pieces.

The panel used existing analyses ${ }^{27}{ }^{28}$ to estimate that it would require about 30 additional feet of overburden to cause such a failure, assuming reasonable concrete strength levels. For purposes of this estimate, the panel estimated that similar overburden failure threshold values would exist for both SSTs and DSTs. Recent WHC tank structural analysis documents indicate that safety factors (on code allowable values) for the regions in which failure is anticipated are on the order of 3 . The experts agreed that code allowable values represent a safety factor of about 1.75 for failure. In addition, they conservatively assumed that stresses in the above documents were caused by a uniform load resulting from 7 feet of overburden (the approximate minimum overburden depth present on the tank dome 
W-(-1) - W

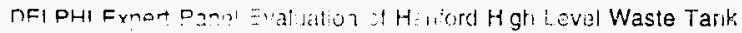

Failurs Modes; and Rielense Countities

crowns). The total load for failure was thas estimated to be $13 * 1.75 * 7=37 \mathrm{ft}$.) or about

30 feet of additional overburden

\section{Concentrated load}

The following were the conclusions from the two-day Delphi meeting:

\section{DOUBLE SHELL CONCENTRATED LOAD}

- Bending (local) @ 800 tons \& soil

- Flattens dome and shears through at 800 ton loads

- Failure $30 \mathrm{ft}$ diameter with addition spalling out to $40 \mathrm{ft}$ diameter

- Liner deforms in holes@ nelson stud locations. Small tearing and cracking@ welds

\section{SINGLE SHELL CONCENTRATED LOAD}

- Bending (local) @ 600?? tons \& soil

- Flattens dome and shears through at greater loads

- Failure $30 \mathrm{ft}$ diameter with additional spalling out to $40 \mathrm{ft}$ diameter

- Concrete \& soil \& concentrated load drop into tank

Following the meeting, additional supporting information was obtained and is presented below.

\section{Single-Shell Tank failure threshold estimates due to concentrated load}

The concentrated load evaluation assesses the impact that a large equipment item, such as a crawler-mounted crane, might have on the tank structures if it were to be placed over the tank to perform necessary maintenance. Leach $1993^{29}$, Appendix C of Appendix E notes that previous structural analyses (RHO $1978^{30}$ and Ramble $1983^{31}$ ) accounted for a concentrated load of 100 tons distributed over a $30 \mathrm{ft}$ radius and 100 tons distributed over $10 \mathrm{ft}$ radius area, respectively. The location for application of this loading condition has been taken to be at the crown of the tank. Given the probability of failure of $=1 \times 10^{-3}$, the load factors for the live load and resistance are 1.7 and 0.9 , respectively.

The panel estimated the average ratio of actual stresses to tensile strength of concrete is 3 . They know all concrete structures witness some degree of degradation. Assuming a $20 \%$ decrease in the concrete strength, SSTs will fail due to 300 tons concentrated load (100 tons * $3 / 1.7 * 1.7$ (live load factor) $/ 0.9$ (strength factor) $* 0.89$ (concrete degradation 
factor)); applied over $10 \mathrm{ft}$ racius area. Th is lad tlattens the dome of the tank and shears through a $10 \mathrm{ft}$ radius area conterd at the crown of the tank. The experts also expect that additional spalling of the concrete could occur out to $20 \mathrm{ft}$ radius area. The experts concluded that the concentidicu luat, cullteic, and some soil will drop into the tan!- No significant air release should result.

Double-Shell Tank failure threshold estimates due to concentrated load

Leach $1993^{32}$, Appendix D of Appendix E notes that previous structural analyses of the DSTs accounted for concentrated live load of 50 tons. The location for application of this loading condition has been taken to be at the crown or apex of the tank. Appendix D does not indicate that this load is to be distributed over a surface area. Becker $1994^{33}$ recommended that a 100 -ton load applied at the apex of the tank over a $10 \mathrm{ft}$ radius area be used. The DSTs have a steel liner that should enbances resistance to this type of loading. The panel estimated that the DST will fail due to 400 tons concentrated load applied over a $10-\mathrm{ft}$ radius. This load flattens the dome and shears through the $10 \mathrm{ft}$ radius area centered at the crown of the tank. Concrete may spall up to a 20 - $\mathrm{ft}$ radius.

\subsubsection{Excessive dome loading findings and recommendations}

1. The probable failure mode for excessive dome loading would be a failure in the haunch area, leading to large pieces (potentially one intact piece) 'settling' onto the waste.

2. It would require on the order of 30 feet of additional overburden on the tank to initiate this failure mode.

3. The SST limit for concentrated loads is $300-600$ tons.

4. The DST limit for concentrated load is $400-800$ tons. 
5. The failure mode for ccrientrated loads is shear of a 10 - $\mathrm{ft}$. radius section under the load.

3. A sing

\subsubsection{Aging scenario}

Aging is the failure of the tank due to loss of strength from material aging. Aging includes long term concrete drying effects and potential corrosion of liner and rebar materials.

\subsubsection{Aging technical basis}

A large sample of tanks with various construction times, techniques, and contractors, and with varied operational histories, has shown no failures indicative of aging that might lead to airborne release. The worst case waste tanks have been subjected to 50 years of operation consisting of cycles of filling and emptying with very caustic waste at temperatures up to $350^{\circ} \mathrm{F}$; some SSTs have been exposed to waste temperatures approaching $600^{\circ} \mathrm{F} .34$ Even in the worst case where the waste temperature approached $600^{\circ} \mathrm{F}$ the temperature of the concrete dome region is less than $350^{\circ} \mathrm{F}$. Present waste temperatures in most tanks, however, do not exceed $200^{\circ} \mathrm{F}$. At this temperature, significant additional degradation is not expected beyond that which has already occurred

Aging effects can be expected to be worst at the waste interface (present or historical), at the locations that have been subject to maximum temperatures, and at sensitized locations (e.g. welds or crevices). There have not been any observed failures attributable to aging.

It can be expected that corrosion of the liners will eventually lead to leakage to the ground. Leakage to the ground is unlikely to lead to air release, as data on Hanford soils has demonstrated extensive retention of radionuclides.

Recent improvements in video technology are enhancing the database of visual information on the interior condition of the tanks. This data has shown no unusual signs of aging. 
The primary failure modes due to aging can be expected to be the same modes as may occur from other initiators. Concrete cracking and spalling with age may actually lead to additional filtered vent paths, reuucing the potentıal Untiltered release trom pressurization events. Likewise, corrosion penetration of the dome liner in the DSTs may lead to additional filtered vent paths.

\subsubsection{Aging findings and recommendations}

1. The expert panel did not identify any unique failure modes leading to atmospheric release due to aging of the tanks.

2. Aging may contribute to tank leakage to the ground in the future.

3. If material aging were to lead to tank failure in the future, the failure modes would be the same as considered for the other initiators; for example 3.2, excessive dome loading.

\subsection{Gas or liquid deflagration}

\subsubsection{Gas or liquid deflagration scenario}

This scenario considers the deflagration of flammable gases or a flammable organic liquid layer on the surface of the waste. Detonation is not the same as deflagration, and is considered a beyond extremely unlikely event. The primary feature that distinguishes these scenarios from the organic nitrate fire considered in 3.6 is the duration of the event. The gas and liquid deflagrations are relatively quick (seconds to minutes) in duration, and add little overall thermal energy to the tank system. Therefore, potential effects due to heating of the tank structures are not significant.

Flammable gas generated and stored in SSTs and DSTs can be released under steady-state conditions or as a gas release event. Assumptions regarding the episodic releases lead to 
wide uncertainiy in the quullity of fl.mulaje gos, and the mixing with oxygen in the tank dome prior to deflagration. 'These assumptions significantly affect the calculated deflagration rates and consecuent tank pressures. Figure 13 shows a typical pressure-time history for a hydrogen deflą,ration in a DST. The pressure history curves are similar for an SST with the exception that dome failure would occur very early, at approximately 10 psi.

Following a deflagration, the tank gas space is hot, and may include condensable combustion products, such as water. As the tank cools, it is possible that the cooling contraction of the gas would exceed the in-leakage ability to maintain the dome space pressure. This might lead to the formation of a vacuum in the tank.

Figure 14 illustrates the calculated pressure differential that may occur due to tank cooling following a deflagration. The curve shows the maximum pressure differential reached as a function of the leakage path effective orifice diameter. Note that the effective orifice diameter for in-leakage may differ from that available for out-leakage, as seals may act differently or cover-blocks that lift from internal pressure may seal with external pressure.

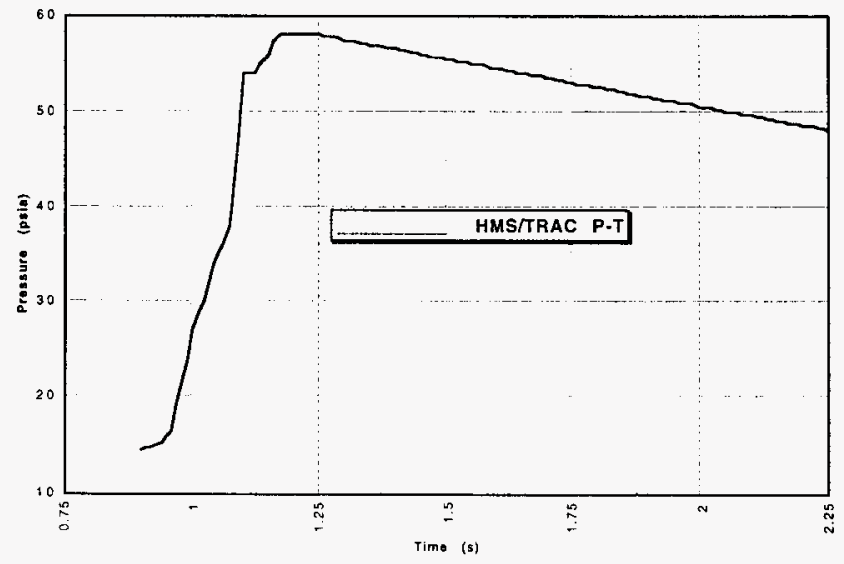

Figure 13: LANL predicted DST pressure following a rapid gas deflagration. 
TANK VACUUM - Large SST .

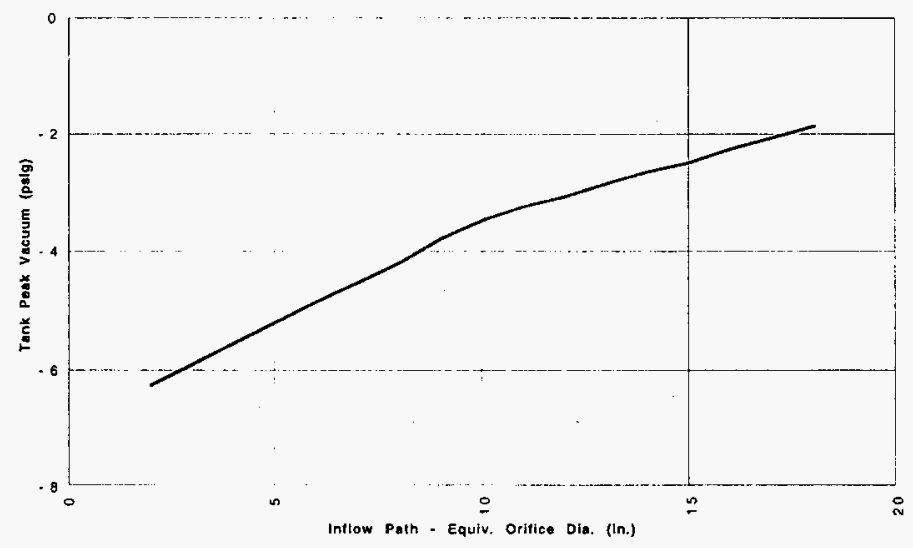

Figure 14: Calculation results for tank vacuum following deflagration.

\subsubsection{Gas or liquid deflagration technical basis}

Tank structural response to an internal gas or liquid deflagration will be somewhat different for SSTs and DSTs. The DSTs design withstands higher internal pressure prior to failure. Also, the DST primary liner influences leakage and concrete spalling behavior.

DST and SST structural behavior is dependent on the details of the deflagration. Potential tank failure modes and limits depend on:

- Peak pressure,

- Pressurization rate,

- Duration of pressure pulse,

- Magnitude of heat generation, 
WHC-SD-TWR-RPT-003, Rev. ?

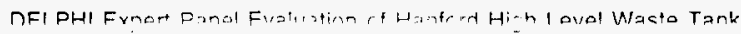

Failure Modes and Releas Quantities

- Duration of heat generation, and

- Rate and magnitude of depressurization.

\section{Cautions for Application of Delphi Tank Pressurization Information}

It was necessary to assume pressurization loads of some limited numerical value to obtain a panel consensus. The panel had to focus on the same accident to achieve a consensus.

The structural panel hopes that the numbers developed are also useful to guide application to safety postulated accidents. The postulated tank failure results could change greatly for significantly higher load cases; especially with very fast pressure rise times. Be aware of the following cautions on the use of any structural numbers/estimates:

- The conclusions are applicable only to failure analysis/limits.

- The conclusions do not address code compliance (ACI, ASCE, ASME, UBC). In most cases. many code limits will be violated.

- The panel assumed best estimate material properties.

- The panel assumed the structure would not be serviceable after the event/load.

Therefore, these conclusions can NOT Apply for Operational Limits. (Significant permanent damage would compromise operational load capabilities.)

\section{Single-Shell Tanks}

The following items were concluded from the two-day Delphi structural sub-panel meeting:

- Dome cracking with distributed pressure venting (analysis static press $11-12$ psi) with overstress of launch rebar.

- Self venting through soil distributed.

- Some post-event concrete spalling inside dome.

- No dome collapse.

Following the meeting, task assignments were made to summarize supporting information, and resulted in the following additional information. 
Failure modes and load limits for the SSTs are based on existing analyse ${ }^{35}$. The analyses predict some cracking with distributed pressure venting and overstressing of rebar (splitting bond failure) in the range of 11 to 15 psig internal pressure. This failure would lead to self venting through the soil. any release through this path would be filtered and distributed (compact sand and gravel).

The post-burn structural response depends on the nature of burn event. In a slow burn event (minutes), with low heat generation. the peak pressure buildup would be reduced by venting through cracks generated in dome. Some concrete spalling inside dome would be expected. Complete dome collapse is not expected, as the pressure is self vented, limiting the strain so that concrete re-bar adherence remains. Many of the cracks would simply close as the pressure reduces and the concrete goes back into compression. There would be concrete spalling.

The panel conclusions were based on existing static structural analysis and on the world failure data described above. Figure 15 shows the results of static analysis of cracking in an SST due to static pressure loading. The cracking was found to progress very rapidly at a pressure slightly above $11 \mathrm{psig}$, indicating a discrete failure pressure. 


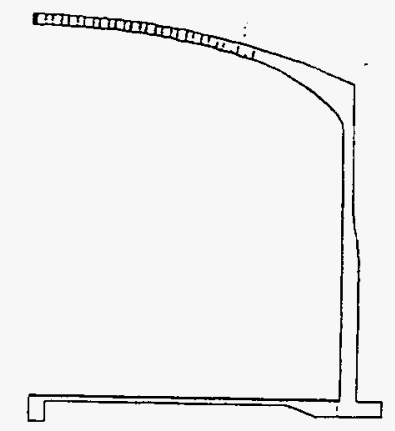

(a) Overall Tank

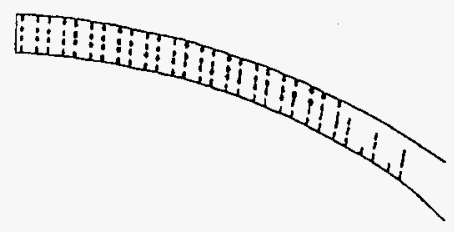

(b) Dome Region

Figure 15: Static analysis of SST cracking indicates gross cracking at slightly above 11 psig.

Figure 16 illustrates the overall failure scenario for the tanks up to $11 \mathrm{psig}$. Pressure increases up to $11 \mathrm{psig}$ are expected to simply cause deformation and cracking of the concrete. At some pressure slightly above $11 \mathrm{psig}$, the tank will crack extensively. This cracking should be sufficient to relieve pressure through the soil, so long as the pressure increase rate is not too great. It will require a dynamic pressurization model, including cracking and pressure relief, to determine the final tank condition for a given scenario. 


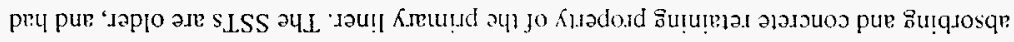

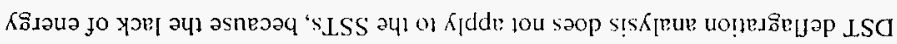

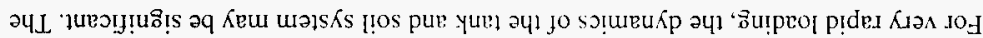

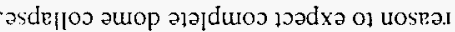

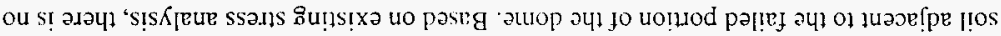
pue [е!

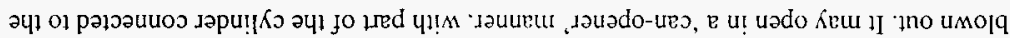

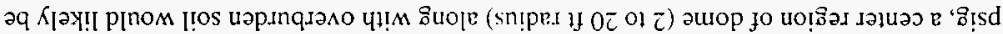

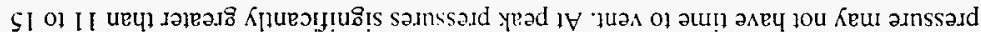

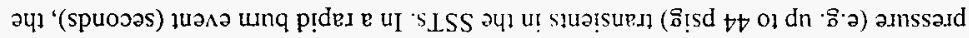

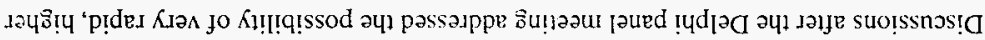

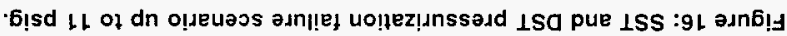

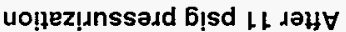

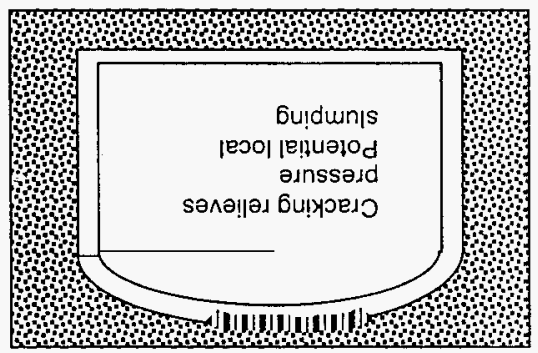

jEUNON

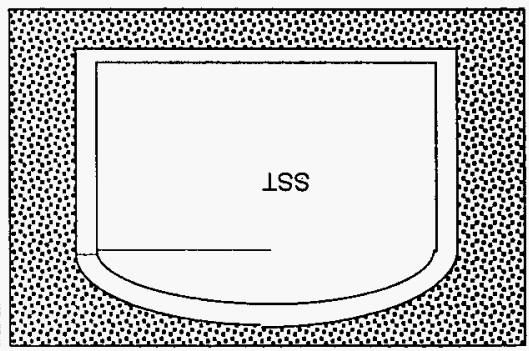

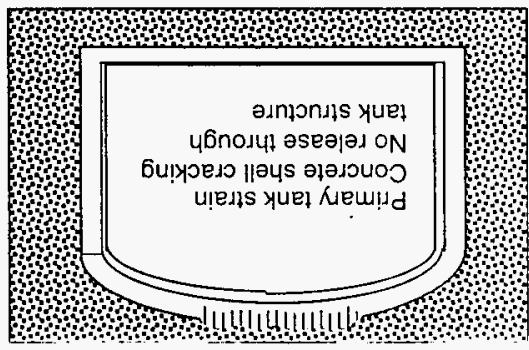

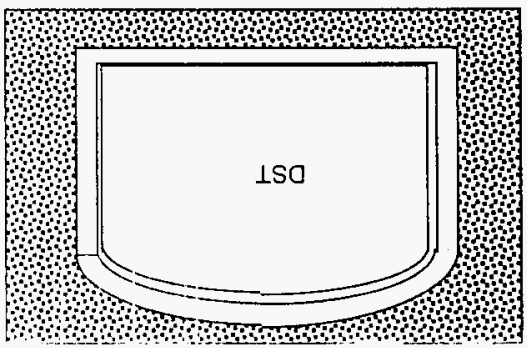

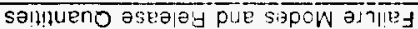

xuE

0 ' 
lower initial material strength than the DSTs. This has not been studied, and was beyond the scope of the Delphi panel charter.

\section{Double Shell Tanks}

The following items were concluded from the two-day Delphi structural sub-panel meeting:

- Rounding of primary liner bottom with rigid body lifting of concrete vault (SY-101 no rebar between wall and foundation not applicable for DSTs with walls tied to foundation). Also, there will be concrete cracking in the dome for all double-shells during pressurization to failure.

- Failure of primary liner along transition weld at $6 \mathrm{ft}$ radius of dome. Partial tear along weld line at approximately 55 to 60 psi.

- The energy of the high pressure air ( 55 to $60 \mathrm{psig}$ ) at failure is such that it is postulated that part of the concrete and soil above the center $6 \mathrm{ft}$ radius of dome will blow out.

- The failure will most likely be one side of a circle defined by a $6 \mathrm{ft}$ radius circle centered at the top of the dome.

The following substantiation information was provided after the two-day meeting, and reviewed by the panel members.

Static loading analysis of the DSTs subject to internal pressure resulted in cracking of the concrete, as illustrated by Figure 17, and deformation of the primary liner. At 60 psig, these analysis indicate the likelihood of a failure in the tank dome due to local stress intensification. Based on the tank design and world failure data, this is expected to lead to the 'can-opener' type of failure seen in the world data for tank failures. 
WHC-SD-TWR-RPT-003, Rev. 0

DELPHI Fxpe+ Panol Fvaluration ef Hanterd High Level Waste Tank

Failure Modes and Release Quantities

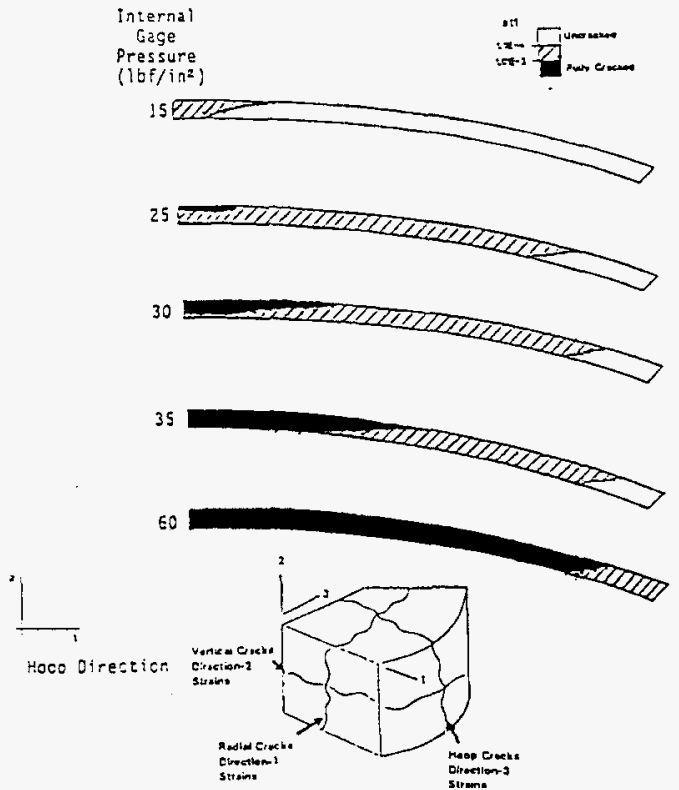

Figure 17: DST concrete dome cracking from static pressure loading analysis. ${ }^{36}$

LANL recently performed thorough analysis of DST deflagrations for tank SY-101 ${ }^{3}$. The expert panel reviewed these analyses. The DST response to a dome burn for SY-101 involved the bottom liner changing shape during the pressure increase. The liner rounded, deforming and lifting the dome and side walls of the tank as rigid bodies, with additional dome displacements due to dome expansion. (Note: SY-101 has no steel reinforcing between the walls and foundation.) Dome concrete was predicted to crack before the primary liner failed. The computer model used by LANL (taken from the WHC developed tank model) predicted that the tank would rebound after maximum pressure is reached, and that dirt would impact the top of the dome, potentially causing failure. This was based on a velocity limit criterion calculated to cause exceeding failure strain energy limits. This criterion alone does not indicate the failure mode that would result. 
In reality, if the tank walls are lifted, the surrounding soil friction and the possibility that soil would partially fill in under the walls, would limit the drop height of the tank dome.

The primary liner would prevent any' spalled concrete from falling and impacting the waste (other than a limited amount at the primary liner tear). It is most likely that the liner would hold the concrete in place, allowing the cracks to seal and the concrete to perform in compression. Even if large quantities of concrete spalled, the primary liner would deform and lower the concrete to the waste, with little potential to create airborne particulate release.

Figure 18 illustrates the expected failure mode sequence for the tanks after 60 psig pressurization.
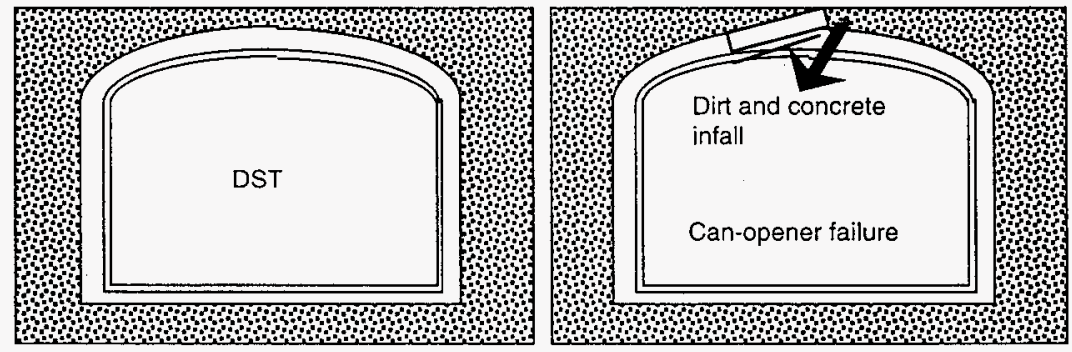

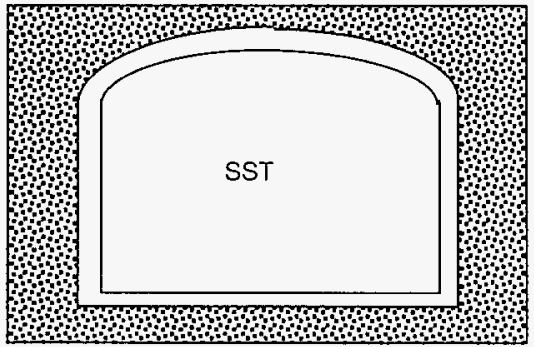

Normal

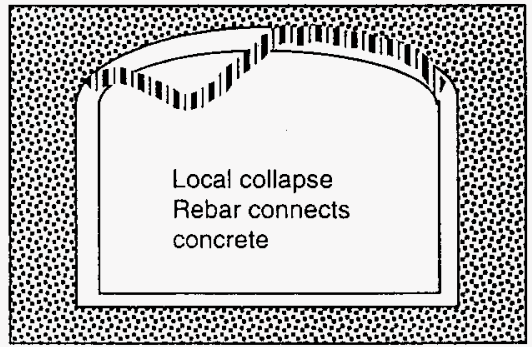

After 60 psig pressurization

Figure 18: Delphi panel estimated failure mode sequence for the SSTs and DSTs up to 60 psig. 
WHC-SD-TWP-POT -

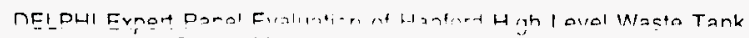

Failure Modes ard Release Quäntities

Internal vacuum

Tank failure with internal vacuum would be subject to the same modes and strength limits as apply for excessive overburden. It is simply an additional downward force on the dome. Based on the calculation of 30 feet of additional overturden to tank failure developed in section 3.2 above, the tanks should not fail under vacuum. That is, they would withstand full atmospheric pressure applied externally due to an external vacuum. This is because soil density exceeds water density, and 32 feet of water is equal to one atmosphere of pressure.

Tank vacuum would also act on the sidewalls of the tank. The tank may be subject to buckling from external pressure on the side walls. Buckling of this nature would cause the walls to crack, spall, and possibly move, potentially leading to local loss of dome support and local slumping. The panel could not envision a substantial potential for a failure mode leading to atmospheric release from this type of external pressure failure.
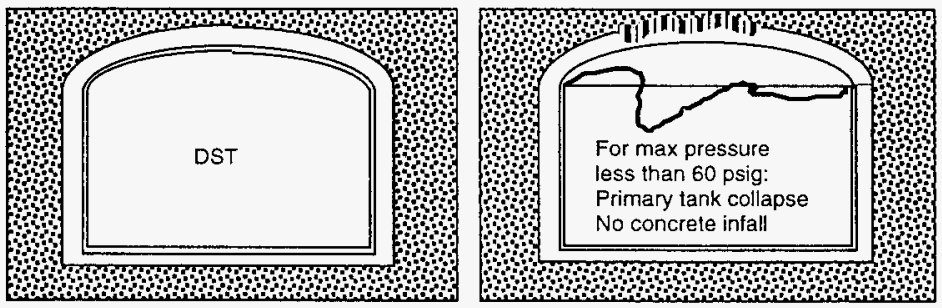

Air flow

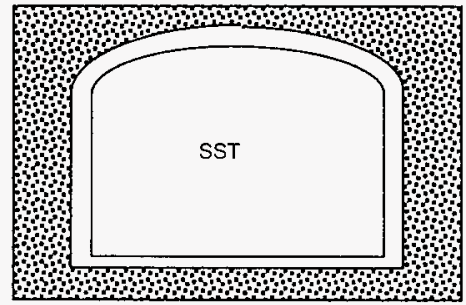

Normal

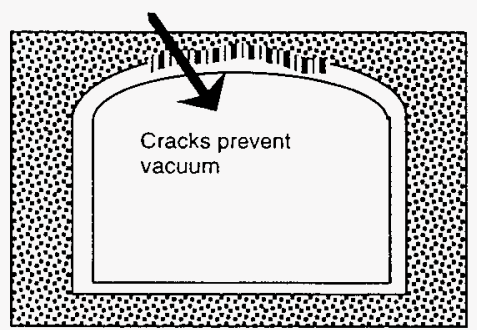

After vacuum following pressurization

Figure 19: Delphi panel expected tank response to vacuum following pressurization 


\subsubsection{Gas or liquid deflagration findings and recommendations}

1. For SSTs, the expected failure mode from gas or liquid deflagration events large enough to cause pressure to increase to 11 to 12 psig is cracking of the upper wall and dome. Unfiltered release would take place through open risers, including lifting of cover blocks. When the pressure exceeds 11 to $12 \mathrm{psig}$, additional filtered release of gases through the soil would occur.

2. For DSTs, the primary tank further reduces the potential for release. These tanks are not likely to fail until pressure reaches about 55 to 60 psig. Below this pressure, the primary tank will bulge, lifting the entire concrete DST dome and side walls. The ultimate failure mode may cause the rapid 'can-opener' partial opening of a flap in the tank dome (to about $30^{\circ}$ ), starting at the large stress intensification introduced by the small riser.

3. If the Hazard Analysis defines very rapid, higher pressure (i.e. $>12$ psi) loading of SSTs, dynamic analysis should be performed to assess failure modes.

4. Tank failure due to vacuum following a deflagration is not likely.

\subsection{Seismic}

\subsubsection{Structural Panel's Conclusions}

The SSTs would not fail unless an earthquake produces an acceleration level of at least 0.6

g. This failure mode is defined as follows:

- Localized shear failure of the wall near the footing.

- Failure of liner at some locations do to wall failure near footing.

- Dome cracking on both the inner and outer face. 
- No continuous large through-the-thickness cracking of dome.

- Some spalling on inner wall of dome due to high dynamic compressive stress. The structural sub-panel concluded the following for the DSTs during the two-day Delphi panel meeting:

- Base of wall shear damage; wall may 'walk.'

- Dome cracking.

- Primary liner holds; no release from the dome.

- Possible leakage may occur, and welds may crack.

- Secondary liner at the wall base would be damaged.

- The above is applicable for a $0.8 \mathrm{~g}$ event.

Following the Delphi structural panel session where the conclusions defined in Section 3.5.1 were reached, additional information was gathered to provide background and support to those conclusions. The discussion that follows is a comparison between the Delphi and the additional information.

\subsubsection{Seismic scenario}

Earthquakes produce dynamic ground movement with various amplitudes and frequencies (of ground movement), leading to horizontal and vertical acceleration that produce forces in structures. The maximum acceleration of the structure is normally the determinant of peak stresses, and therefore failure, in structures, but the duration of the strong motion can also be important. Structure design, including natural frequencies, and soil-structure interactions impact the relationship of structure acceleration to ground acceleration. 


\subsubsection{Seismic technical basis}

Technical information about seismicity of the Hanford site is very good compared to most locations in the world. This is due to extensives study over a long term by the DOE and for the nearby commercial nuclear power plants. This information includes the development of probable earthquake accelerations vs. annual frequency for specific areas on the Hanford site.

Figure 20 illustrates the latest study to predict the relationship between earthquake frequency and acceleration for the Hanford tank farms. The mean annual frequencies for ground accelerations of $0.2 \mathrm{~g}, 0.6 \mathrm{~g}$, and $0.8 \mathrm{~g}$ are (respectively) $5 * 10^{-4} /$ year, $3 * 10^{-5 /}$ year, and $1.5 * 10^{-5} /$ year. This converts to mean recurrence intervals of about $2,000,30,000$, and 60,000 years.

The expert panel based seismic conclusions on extensive previous analysis. Many Hanford tank design and safety analyses assess seismic capability. Several of the experts were authors and contributors to these analyses. A recent summary ${ }^{38}$ includes references to thirty-six significant structural analyses of the Hanford tanks. Two additional reports ${ }^{39.40}$ summarize much of the structural information developed through 1994.

The panel evaluated differences between the SST and DST designs, and existing SST seismic analysis to conclude that failure modes would be similar for SSTs. Since some SSTs were designed with less rebar than the DSTs, the panel estimated that the comparable limit for the SSTs is about $0.6 \mathrm{~g}$. The panel based their overall evaluation and consensus process on past seismic analyses of various tanks, engineering judgment, and past performance of such structures during earthquakes. The general definition of when tanks begin to fail was the initiation of failure due to yielding of rebar and some crushing of concrete as defined above in Section 3.5.1. 
WHC-SD-TWR-RPT-003, Rev. 0

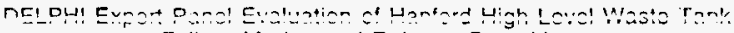

Failure Modes and Release Quantities

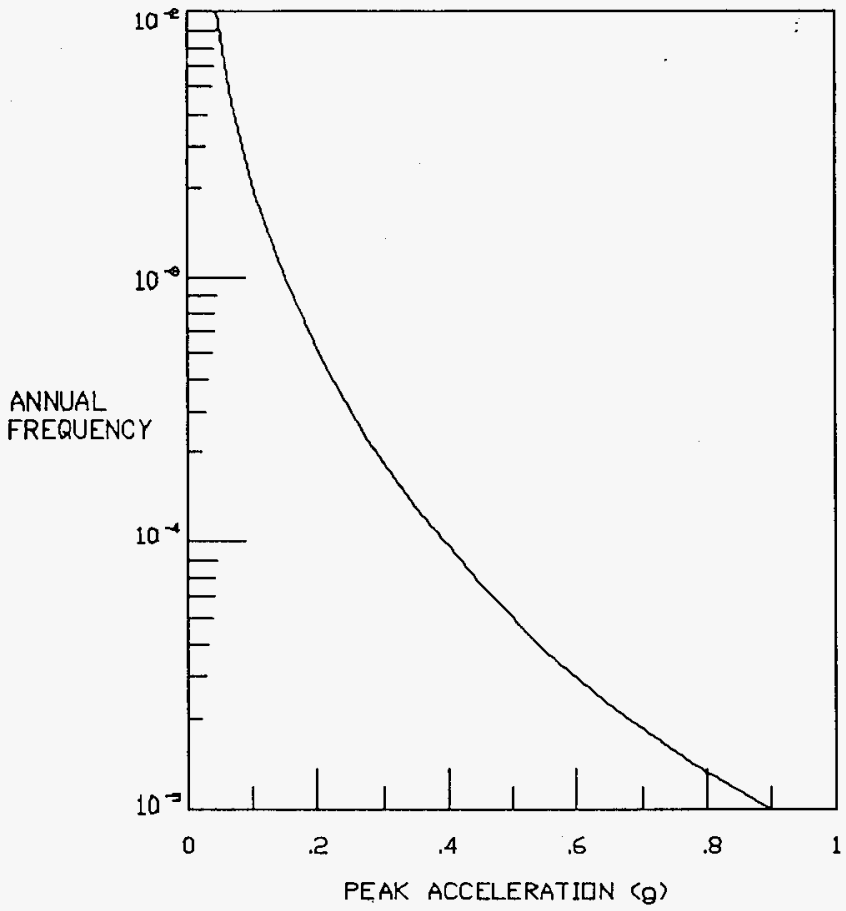

Figure 20: Earthquake acceleration vs. annual frequency for the Hanford tank farms is one basis for the low probabilities of seismic tank failures.

\section{Single-Shell Tanks}

The major difference between the SSTs and DSTs is the SSTs have a positive shear connection between the tank walls and footings. The DSTs walls have no positive connection and can move inward and outward on top of the footing. Based on single-shell and double-shell seismic analyses, higher loads are applied by the interaction of the soil and tank at the walls near the footings. This leads to initial failures at that location. At a horizontal acceleration of $0.25 \mathrm{~g}$, an elastic seismic analysis ${ }^{41}$ showed that the $241-\mathrm{AX}$ 
SSTs meet the code requirements. Althougt the process of DOE Standard 1020-94 was not specifically followed, the fact that under se s.mic loading code requirements are basically met implies that the requirements of the Standard are also achieved.

The seismic performance goal for the Hanford Tanks $s^{42}$ is $10^{-4}$ annual probability that the tanks could be damaged such that they could not perform their intended function of containment. The $10^{-4}$ per year acceleration for the tank sites is approximately $0.47 \mathrm{~g}$. Thus, the SSTs would experience the damage as described if accelerations were in the $0.6 \mathrm{~g}$ range. In addition, a fragility study by EQE of the 241-AX tanks showed that there is a $95 \%$ high confidence of low probability of failure at $0.43 \mathrm{~g}$ and a median confidence of low probability of failure at $0.71 \mathrm{~g}$, where failure is defined as gross leakage of the tank. The EQE fragility curves were not a part of the Delphi session, and thus, provide confirmatory support of the Jevel of damage and corresponding acceleration level.

Because some of the SSTs have been taken to high temperatures, and are older then the DSTs, using a controlling acceleration of $0.6 \mathrm{~g}$ is appropriate for the SSTs. The EQE fragility report of the SSTs further states: "Loads from vertical seismic input and hydrodynamic response of the tank contents were found to have no impact on the failure mode and only a small impact on the estimate of the factor of safety."

As noted above the Delphi structural expert panel conducted its process independent of the discussions contained herein. Shortly after the Delphi process had occurred, a report was made available to the panel. This report was the Wesley and Honegger (1993) report on the probabilistic capacity of the 241-AX SSTs to withstand seismic excitation, which included fragility curves for the tanks. The objective of a fragility evaluation is to estimate the peak ground motion acceleration value for which the seismic response of the tanks exceeds their capacity, resulting in failure. Failure was defined by Wesley and Honegger as gross leakage from the tank which was further defined as:

The concrete tank failure mode resulting in gross leakage was circumferential tensile failure of the tank dome near the haunch (Honegger 1996). The circumferential tension failure was assumed to occur when the reinforcing steel reaches its median yicld strength. The yield strength of the rebar as sold is called out as $40 \mathrm{ksi}$. However, to always assure that $40 \mathrm{ksi}$ exists, the rebar is found to 
W'C-SD-TWR-R'T-003, Rev. 0

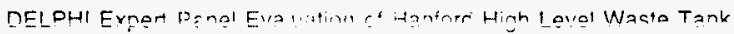

Failure Modes and Fielease Quantities

have a median yield strength of $48.8 \mathrm{ksi}$, thus, Wesley and Honegger used this value as initiation of yield. While this appears to be a conservative definition of failure, when Wesley and Honegger determined the median capacity, they allowed for a strength increase factor of 1.97 , which represents the ratio of ultimate strength to the stress calculated at $0.25 \mathrm{~g}$, and an inelastic energy absorption factor of 1.68 , which represents the energy absorbed after the rebar has yielded. Thus, failure is really defined as failure of the steel at ultimate strength.

The results of the Wesley and Honegger study showed that the best estimate of the median ground acceleration capacity of the SST's was $0.95 \mathrm{~g}$ and the high confidence low probability of failure (HCLPF) was estimated to be $0.43 \mathrm{~g}$. If the SSTs were to experience an earthquake having a median ground acceleration of $0.43 \mathrm{~g}$, the HCLPF means that there is a $95 \%$ confidence that the chances of tank failure are no more than a $5 \%$, or, if there were 100 identical tanks, there is a $95 \%$ confidence that no more than 5 would fail. This does not indicate how many will fail. If 100 earthquakes with a given HCLPF acceleration were to occurred to a single tank, there is a $95 \%$ confidence that the tank would not fail in at least 95 of them.

The best estimate of the median ground acceleration capacity of a tank is the best estimate of how large of an earthquake a tank can experience before it fails in the defined failure mode. Thus, the Wesley's and Honegger best estimate of when a flexural failure of the dome at the haunch was $0.95 \mathrm{~g}$ for the SSTs. This estimate is not incompatible with the Delphi estimate of $0.6 \mathrm{~g}$ 's as the failure mode when you compare the difference in the definitions between what the Delphi structural panel assumed and what Wesley and Honegger assumed. The Wesley and Honegger definition of failure was more severe than the Delphi structural panel. That is, the Delphi panel used a descriptive damage state that would be something like half way between the yielding of rebar and medium capacity defined by applying factors, such as the strength and inelastic absorption factors that give ultimate capacity. In addition, the location of failure defined by Wesley and Honegger was based on an early 1980 analysis of tanks 241-AX. The Delphi used the results of much later and more rigorous analytical methods.

In summary, the SST failure mode at the $0.6 \mathrm{~g}$ acceleration includes: 
WHC-SD-TWR-RPT-003, Rev. 0

DFI PHI Frnot Pand Fyalr.at nn of itaniond Hinh I evel Wasto Tank

Failure Modes and Release Quantities

- Localized shear failure of the wall near the footing.

- Failure of liner at some locations due to wall failure near footing.

- Dome cracking on both the inner and outer face.

- No continuous large through-the-thickness cracking of dome.

- Some spalling on inner wall of dome due to high dynamic compressive stress.

\section{Double-Shell Tanks}

Panel members evaluated existing data and concluded that the acceleration for failure in shear at the lower wall is about $0.8 \mathrm{~g}$. Such failure is not expected to be catastrophic because no major pathways to the atmosphere are opened. The tank may settle, and the secondary liner would probably tear around the knuckle at the foundation-wall juncture. The existing DSTs have a sliding interface at this juncture, so the wall should move (walk).

The panel based this conclusion, in part, on recent analysis of the MWTF (Multi-purpose Waste Tank Farm, a proposed new facility). These tanks are similar to the existing DSTs, and were analyzed to $0.39 \mathrm{~g}$ seismic loading. Results show little margin for in-plane shear in the lower wall. This analysis is unrealistically conservative because it does not use inelastic capacity factors. Such factors can be substantial -- two or so, depending on the performance category -- accounting for ductility in a seismic loading environment as opposed to a load controlled environment. (Code allowables address a load controlled environment.) (See UCRL- $15910^{43}$ or BNL $1993^{44}$.) Using this factor of about two leads to $0.8 \mathrm{~g}$ as the acceleration where shear failure might begin. The panel estimate is based on collective expert judgment. The panel believes degradation from temperature over time for the DST is minor, because analysis uses 28 day concrete properties. Concrete strength actually increases with aging, and the operational tank temperatures were not high enough to cause degradation beyond this strength increase. 


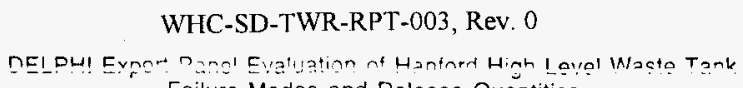

Failure Modes and Release Quäntities

The panel addressed dome integrity under vertical loading because of the possibility of dome collapse. Recent analysis (ASA Phase I) shows a safety factor of about three for static soil loading compared to code allowables. This factor is based on the section loads in all sections of the haunch relative to the PM (Force-moment) diagrams. Failure is expected when the entire haunch yields in hoop tension.

The analyses reported above compared calculated loads to design code allowables. Allowables include safety factors of 1.5 to 2.0 , considering average material properties. Consequently, the dome should have a $3 \mathrm{~g}$ cushion for vertical seismic loading. Dynamic amplification may reduce this by up to one half, so $1.5 \mathrm{~g}$ could be limiting for the dome. The analyses consider the soil deadweight without structural resistance.

The panel considered the possibility that the vertical earthquake component might equal the horizontal component. (Previous analyses usually set the vertical acceleration at two thirds of the horizontal. The recent Northridge earthquake observations indicate in some cases the accelerations may be equal.) Rough calculations for buckling ${ }^{45}$ of the dome suggest that the static margin against buckling may be as high as an order of magnitude. Therefore, buckling would not occur except for ground motion much greater than those causing the haunch failure. Consequently, shear failure in the wall without dome collapse is the controlling failure mode at $0.8 \mathrm{~g}$. Concrete cracking may occur. The primary tank would be intact at the dome, so no pathway upward and out is envisioned except for some minor cracking at welds.

As in the case of the SSTs, fragility studies were also conducted and made available to the structural panel. This report was the Wesley and Nakaki (1992) report on the probabilistic capacity of the 241-SY-101 DST to withstand seismic excitation and hydrogen burn. Like the SSTs, failure was also defined by Wesley and Nakaki as gross leakage from the tank which was further defined as:

The primary liner failure mode that results in gross leakage was a shear buckling at the top of the tank where it joins the dome. The concrete tank failure mode resulting in gross leakage was a flexural failure of the dome at the haunch caused by bending moments at the haunch. When Wesley and Nakaki determined the median capacity, they allowed for a strength increase factor of 8.0 , which in this 
WHC-SD-TWR-RPT-003, Rev. 0

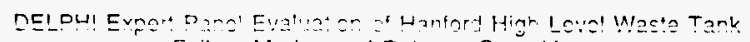

Failure Modes and Release Quantities

case represented the ratio of ultimate strength to the stress calculated at $0.20 \mathrm{~g}$ (The site criteria had been reduced from $0.25 \mathrm{~g}$ to $0.2 \mathrm{~g}$ at the time), and was significantly higher than the value used for the SSTs. The same inelastic energy absorption factor was used for the DSTs as for the SSTs.

The results of the Wesley and Nakuki study showed that the best estimate of the median ground acceleration capacity of the DSTs was $2.7 \mathrm{~g}$ and the high confidence low probability failure (HCLPF) was estimated to be $1.05 \mathrm{~g}$. Again, these estimates are not incompatible with the Delphi estimate of $0.8 \mathrm{~g}$ 's as the failure mode when you compare the difference in the definitions between what the Delphi structural panel assumed as failure and what Wesley and Nakaki assumed as failure. However, it would appear that either the Delphi structural panel was more conservative when estimating the DST capacities or that Wesley and Nakaki were less conservative.

Additional references $46,47,48,49,50,51,52,53$ support the conclusions reached by the panel, and provide supporting data.

\subsubsection{Tank Failures Using PRAs}

A third report was also provided to the structural panel after the Delphi session occurred. This report is know as the "LANL PRA" (MacFarlane, et al., 1995). MacFarlane, et al. used the results of the reports developed by Wesley and Nakaki (1992) and Wesley and Honegger (1993) and interpreted the definition of yielding of rebar as failure as dome collapse. This assumption may be a little conservative since it assumes that the dome would shear off and fall straight down into the tank as a complete section, but is reasonable based on all the uncertainties.

Because some confusion occurred during the draft reviews of this report when interpreting the Delphi results and the results shown in the LANL PRA report that was based on the fragility curves discussed above, the following discussion is provided for clarification.

The probabilities shown in the table on page 4-73 of MacFarlane, et al. represents the annual probability of failure of failing exactly " $n$ " number tanks from all earthquakes 
(Kindinger 1996 and see the discussion tcp of page 4-70) of MacFarlane, et al.). Thus, the probability of $: .03 \mathrm{E}-5$ is the annual frequency of exactly four tanks failing from all earthquakes. It does not represent the probability of a single earthquake causing four tanks to fail. The median failure frequencies from all fragility curves allow for determining the median failure frequency at the upper bound of an acceleration range. Thus, for a given acceleration range there is a failure frequency that can be considered a probability of failure verses a probability on no failure. Since there are only two outcomes, failure or no failure, and there are 149 tanks, the binomial distribution is used to calculate the probability of failing exactly " $n$ " tanks when given that the earthquake acceleration occurs. Thus, the probabilities for failing one tank, two tanks, three tanks and so on, all the way up to failing 149 tanks when a given acceleration occurs are calculated. At this point you will then have the conditional probability on " $n$ " tanks failing (n varying from 1 to 149), i.e., given a certain level earthquake acceleration has occurred. Then using the mean frequencies for each acceleration range, the annual frequency of failing 1 to 149 tanks for each earthquake range is calculated. Then these frequencies are summed across all acceleration ranges to calculate the annual frequency of tank failures from all earthquakes. Thus, the likelihood of failing a certain number of tanks, or at least one tank, from all possible earthquakes can result in a low annual frequency. This annual frequency is not the annual frequency of an acceleration level, taken from a seismic hazard curve, that would cause the tanks to fail.

\subsubsection{Seismic findings and recommendations}

The panel concluded that the following modes of failure apply to DSTs for earthquakes with peak accelerations up to $0.8 \mathrm{~g}$ :

1. Shear damage near the base of the wall; wall may 'walk,' that is, translate horizontally.

2. Dome cracking may occur due to the dynamic flexing of the dome.

3. The primary liner would hold and prevent concrete drop into the waste. It would also prevent release of waste through the dome. 
4. Dome welds may crack, leading to possible leakage of material from the tank. Atmospheric release would be unlikely because there is no driving force.

5. The secondary liner at the base of the wall could be damaged due to movement of the wall.

The SSTs should show similar failure modes (except for item 3 ), with the fragility limit at about $0.6 \mathrm{~g}$. Any release would be filtered through concrete cracks in the side wall and dome.

\subsection{Organic nitrate}

Organic nitrate compounds are known to exist in some tanks. If ignited, the burning of these compounds can generate significant temperatures and pressures depending on the vent capacity of the tanks.

\subsubsection{Organic nitrate scenario}

The organic nitrate scenario is initiated by ignition of the nitrate waste stored in the tank. There is sufficient oxidizer in the waste that a burn reaction is possible without external oxidizers. The potential for ignition is still under investigation. The scenario considers ignition of the waste near the center of a tank, with outward progression driven by self heating and a spreading ignition front.

Once ignited, it is assumed that the reaction will drive off moisture as the burn progresses. Therefore, the analysis results in an acceleration overall reaction due to the increase in reaction area as the diameter of the reaction surface increases. The reaction is assumed to consume all of the available organic nitrate. The reaction is an energy source, and might provide a driving force for release of reaction products. 
Since this reaction reaches very high temperatures, and is potentially sustained over a period of thousands of seconds, it creates the potential to substantially increase structure temperatures. Increased structure temperatures can lead to loss of strength, and potential tank failure. Heat transfer within the tank determines the portions of the tank to heat first, and may affect the potential failure modes.

Figures 21 and 22 show the results of calculations of organic nitrate reactions. Note the relatively long duration of the transient as compared to flammable gas deflagration. Also note that gas temperatures are estimated to reach as high as $700 \mathrm{~K}$.

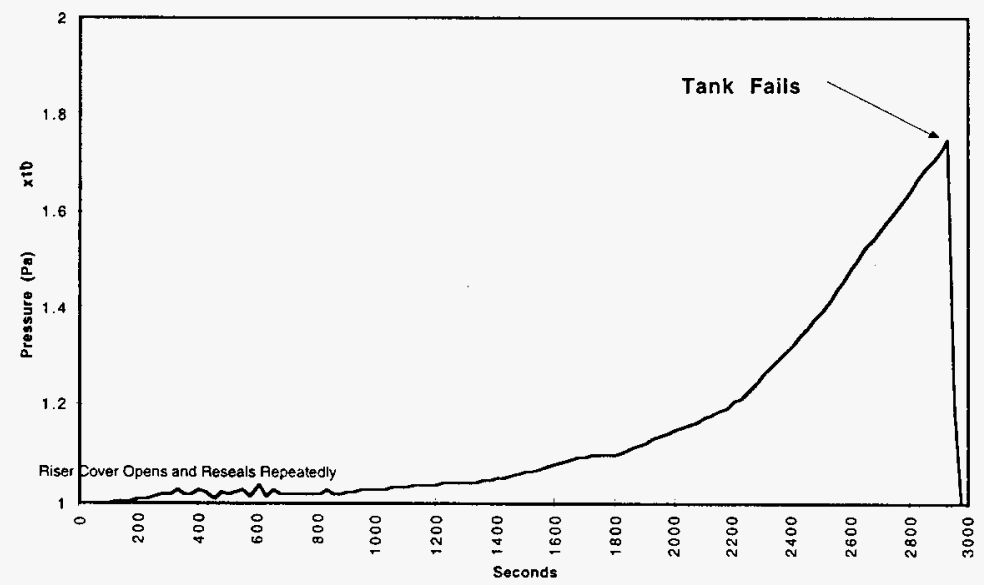

Figure 21: WHC calculation of pressure transient for organic waste burn shows long term pressure increase as reaction increases with time.

Figure 22 shows calculated temperatures in a slab subject to calculated gas temperatures in a tank. Note that there is substantial delay in the increase of concrete temperatures. While the surface temperature is predicted to increase over $200 \mathrm{~K}$ for this transient, the concrete 
temperature one inch from the surface $(2.5 \mathrm{~cm})$ only increases $100 \mathrm{~K}$, or 180 degrees $\mathrm{F}$ over this time.

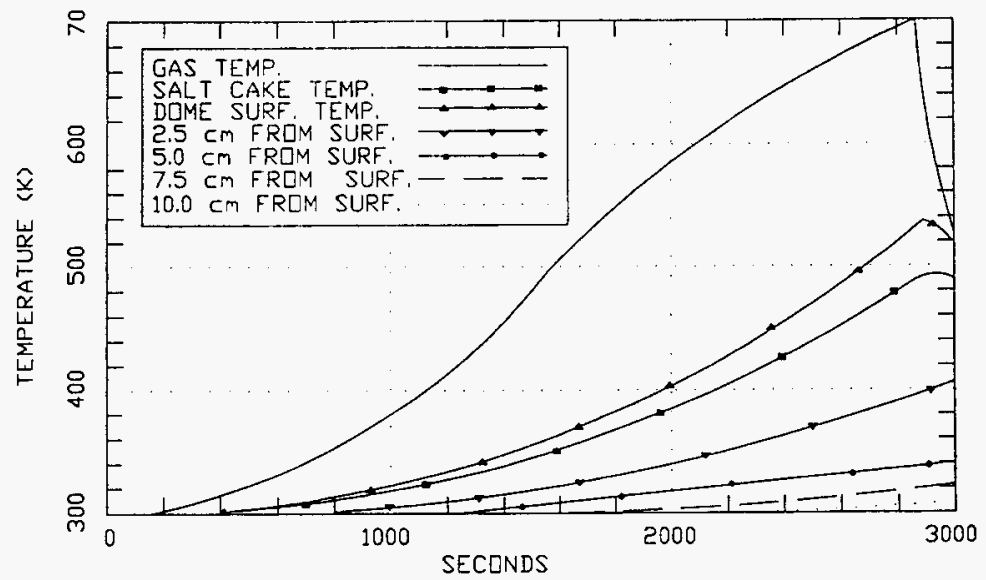

Figure 22: WHC calculated temperatures during organic waste burn, demonstrating the potential for high structure temperatures.

\subsubsection{Organic nitrate technical basis}

An organic nitrate burn is fundamentally different from a gas or liquid deflagration because high heat generation over an extended period of time (hours) could heat the tank structure. Heat up of the structure to temperatures greater than 350 degrees $F$ would lead to reduced concrete strength and stiffness. Rebar strength would also be reduced by increased temperatures. If this loss of strength propagates through the tank structure, wall strength could be reduced to the point that the dome 'sinks.' That is, the supporting side-wall may collapse and allow the dome to follow it down. If the dome temperatures were to get high enough, dome collapse could occur. 


$$
\text { WYC-SD-TWR-Po-_003, Rev. } 0
$$

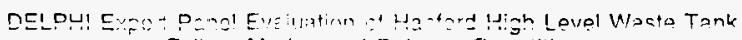
Failure Mole:s and Rele se Quantities

Based on observations of reinforced concre strucures that have failed, dome collapse from high temperature wculd most likely be a progsressive failure, leaving the dome as a set of large blocks conneced by the rebar. The overburden would likely fill in the cracks from the top as the dome sinks. There is no evidence that this ultimate failure mode would lead to large airborne releases of the waste. [The structural panel made no attempt to estimate releases through normal vent paths.]

The current release-transport model used for preliminary analysis of organic nitrate burns uses very few nodes and no real representation of the geometry. The panel are unable to determine if the tank dome or the sidewall would experience the greater loss of strength from this model, and thus are unable to predict the mode of failure.

If this accident sequence is of high enough probability to be considered in the accident analysis, a more representative release-transport model should be used to predict temperatures in the tank dome and haunch areas. The predicted temperatures can then be used to estimate the failure modes (i.e. haunch vs. dome), and the times or temperatures of failure.

For the DSTs, the temperatures predicted by the model remain modest relative to the primary tank melting temperature. Thus, the primary tank is likely to remain intact, leading to little potential for airborne release through other than the normal vent paths.

\subsubsection{Organic nitrate findings and recommendations}

1. The structural expert panel currently does not have an established analysis basis for concrete tank failure modes in this temperature range, without additional structures and materials work.

2. For the DSTs, regardless of the failure mode, airborne release due to ultimate failure should be contained by the ductile primary tank. 
WHC-SD-TWR-RPT-003, Rev. 0

nel Dul Frnor Danol Fual atian af Hanford High Level Waste Tank

Failure Modes and Release Quantities

3. If the final hazard analysis necessitates the analysis of these scenarios in the FSAR, a more detailed release-transport model of the tank is needed to predict the failure mode. Also, additional structural and materials analyses are necessary. 


\section{Release quantities}

\subsection{Delphi questions release quantities}

The first round of questions revealed a wide range of uncertainty in the quantity of release. First round estimates of the median release quantity varied by over four orders of magnitude. Panel discussion of the round I results led to two estimates of release quantity for round two. Panel members made separate estimates of the release quantity for the DSTs and for the SSTs.

The estimates for round II were evaluated in terms of the mean and standard deviation. A relatively large standard deviation on the seismic release estimate led to a discussion and determination that at least one panel member had estimated the release for a multitude of tanks failing, while others had specified their estimate on a per tank basis. The panel agreed that it would be more meaningful to present the results in terms of the median release and a logarithmic variance. These statistics are intended to moderate the influence of extreme estimates.

Data in the two median columns of Table 3 indicates that, contrary to the expectations of some of the panel, the estimates for the median releases from SSTs and DSTs are nearly the same. While the data from round II still included some isolated large release quantities, the median values presented in Table 3 are representative of the data. The largest variance is in the seismic release, because after round II the panel discovered that one or more of the estimators estimated for all tanks.

Table 3 presents a reduced standard deviation, rather than the standard deviation of all of the data points. Extreme data points (more than a factor of three larger than the next sequential data point) were eliminated. Only a few extreme values were eliminated from the standard deviation calculation by this step. The relatively large standard deviations occur because the potential for dome collapse was still considered a reality at this point in the deliberations, and at least one of the experts chose to input a number of $100 \mathrm{~kg}$. 
WHC-SD-TWR-RPT-003, Rev. 0

DELPHI Expa+ Danal Evaluation of Hanford High La':a! 'n! as:o Tank

Failure Modes and Release Quantities

Table 3: Delphi round II release estimates for DSTs and SSTs demonstrated substantial convergence

\begin{tabular}{|c|c|c|c|c|}
\hline & \multicolumn{2}{|c|}{ DSTs } & \multicolumn{2}{|c|}{ SSTs } \\
\hline & $\begin{array}{l}\text { Median of } \\
\text { Median } \\
\text { Release }(\mathrm{kg})\end{array}$ & $\begin{array}{l}\text { Reduced } \\
\text { standard } \\
\text { deviation }\end{array}$ & $\begin{array}{l}\text { Median of } \\
\text { Median } \\
\text { Release (kg) }\end{array}$ & $\begin{array}{l}\text { Reduced } \\
\text { standard } \\
\text { deviation }\end{array}$ \\
\hline Aging & 0.75 & 35 & 1 & 17 \\
\hline Seismic & 10 & 41 & 10 & 49 \\
\hline $\begin{array}{l}\text { Flammable Gas } \\
\text { Deflagration }\end{array}$ & 10 & 32 & 7.5 & 34 \\
\hline $\begin{array}{l}\text { Organic } \\
\text { solvent burn }\end{array}$ & 5 & 4.6 & 5 & 44 \\
\hline $\begin{array}{l}\text { Organic nitrate } \\
\text { burn }\end{array}$ & 10 & 5.5 & 15 & 32 \\
\hline Load drop & 1 & 0.5 & 1 & 3.3 \\
\hline Uniform load & 1 & 22 & 1 & 36 \\
\hline $\begin{array}{l}\text { Concentrated } \\
\text { load }\end{array}$ & 1 & 4.4 & 1 & 4.8 \\
\hline
\end{tabular}

\subsection{Re-estimates of release quantities}

The release quantity panel assessed existing calculations and used data from those calculations with the new failure modes to estimate release quantities. Two situations were estimated; both resulting from overpressure failure. Structural results demonstrate that only one scenario, gas phase deflagration, has the potential for a significant airborne release (could breach the waste tank structure) for both the DSTs and SSTs.

A second scenario, the uncontrolled reaction of solid organic-nitrate and nitrite salt, has the potential for serious deleterious effects but there is currently insufficient information to evaluate the probability of such an event (the organic-salt mixture must be adequately dry and contain a sufficient organic material distribution to allow the reaction to propagate.) 
The release sub-panel divided calculation of the airborne release into time periods:

1. The airborne materials vented during breach of tank integrity,

2. The airborne materials vented during the volume displacement resulting from debris entering the tank, and

3. The airborne materials drawn from the tank by the passage of air over the opening (Bernoulli's effect).

\subsubsection{DST scenario and release - 'Can-Opener' failure of DST at top center of dome}

Figure 23 illustrates the model for air release from a DST following deflagration. The panel used this model to estimate air release quantities with the 'can-opener' failure mode. The figure is broken into three regions by the two large boxes. The upper region (blocks number 1 through 8) illustrates the process for the tank pressure and flow calculations. The lower large box (blocks number 10 through 15) illustrates the process steps for calculating the activity of the gas leaving the tank free volume. Process block 20 illustrates the step for calculating the mass of waste above the tank available for air transport.

The model has feedback connections from blocks 4 and 7 to block 3 The presence of feedback means a dynamic calculation is necessary to perform the calculation accurately. Block 12 of the model is a time delay, which would also require a dynamic (transient) model to accurately predict results. The panel's model is limited to a set of static calculations. 


\subsubsection{Qverall model assumptions and calculation inputs}

\subsection{Assumptions}

1. Free volume of air above waste: $40,000 \mathrm{ft}^{3}$, or $1133 \mathrm{~m}^{3}$

2. Physical form of contents: High density aqueous solutions, density of $1.3 \mathrm{~g} / \mathrm{cm}^{3}$ $\left(1300 \mathrm{~kg} / \mathrm{ni}^{3}\right)$

3. LANL assumed a mass as high as $350 \mathrm{~g}$ may be airborne in the tank during rotary drilling (sampling).

4. Liquid breakup is a function of the energy density imparted to the liquid, and the energy density behaves in the same manner for the impact of solids onto the surface (a conservative assumption since the liquid is compressible and absorbs some of the energy by displacement rather than fragmentation), release fractions are calculated for the free-fall impact of various sizes of concrete with/without the soil overburden.

5. The volume of the debris that enters the tank after venting includes all the debris from the failure of the concrete + the overburden from a 12 -ft diameter column.

6. Solid, dried, surface contamination on the steel liner of the tank that can be released by flexing of dome or wall during pressurization and depressurization (Block 11 of the Figure 23 model) is not included. The salt may be dislodged from the surface by stress during expansion due to pressurization and be made airborne by rapid flexing during depressurization. Data (e.g. the surface contamination level, the size distribution of contamination, and physio-chemical characteristics of the contaminant) to evaluate the contribution from this source is not available.

Input Data

1. Tank diameter, $\mathrm{d}=75 \mathrm{ft}$

2. Area of waste surface $=(\pi / 4)\left(\mathrm{d}^{2}\right)=0.7854\left(75 \mathrm{ft}^{2}\right)=4418 \mathrm{ft}^{2}$ 


\subsection{Initial Conditions}

Airborne activity present in the free volume:

1. Measurements of airborne activity in undisturbed tanks indicate a concentration of $1 \mathrm{E}-8$ $\mathrm{Ci} /$ liter. The prevalent airborne nuclide in the waste is ${ }^{137} \mathrm{Cs}$. The total airborne activity is $[1 \mathrm{E}-8 \mathrm{Ci} /$ liter $]\left[1 \mathrm{E}+3 \mathrm{liter} / \mathrm{m}^{3}\right]\left[1133 \mathrm{~m}^{3}\right]=1.1 \mathrm{E}-2 \mathrm{Ci}$.

2. Mass airbonne during sampling. The nominal mass concentration is $309 \mathrm{mg} / \mathrm{m}][(350$ $\left.\left.\mathrm{g} / 40000 \mathrm{ft}^{3}\right)\left(35.31 \mathrm{ft}^{3} / \mathrm{m}^{3}\right)\right]$.

3. High mass concentrations may be found when an energetic process provides a continuous source of material. The sampling process used in the waste uses a drill string that deploys various rotary speeds dependent upon the difficulty in penetrating the sample material. Aqueous solutions do not require drilling but are simply pushed through the liquid. Dome drilling into solid materials uses a bit that has a continuous groove to aid in expelling the material penetrated and uses higher speed that flings the materials in the grooves by centrifugal force. The bits used for waste tank sampling are relatively smooth, large diameter ( $3 \mathrm{inch}$ ) tubing. Not withstanding, some limited volume around the tube may have a higher mass concentration due to the shedding of liquid clinging to the tube. If this volume was 10 diameters ( 30 inches from the center of the tube), it represents:

- Area of higher mass concentration $=0.7854(2.5 \mathrm{ft})^{2}=4.9 \mathrm{ft}^{2}$

- Ratio of surface of high mass area to waste surface $=4.9 \mathrm{ft}^{2} / 4418 \mathrm{ft}^{2}=0.0011$

- The volume of the higher mass concentration represents 0.0011 of the $1133 \mathrm{~m}^{3}$ free volume.

- Additional airborne mass due to high mass concentration volume $=$ $0.0011\left(1133 \mathrm{~m}^{3}\right)\left(309 \mathrm{mg} / \mathrm{m}^{3}\right)=0.385 \mathrm{~g}$ 
The release sub-panel did not recalculate flammable gas deflagration. They took representative results from a recent $L .4 N L$ analysis. The output of the deflagration model cover blocks 1, 2, and 3 on the Figure 23 rodel.

\subsubsection{Materials vented from the DST during breach of tank integrity}

The initial materials in the tank free volume come from two sources:

1. Airborne activity present in the free volume, at all times (feed to block 14), and

2. Airborne mass from activities being performed at the time of the deflagration (feed to block 14.)

The activity from the two sources is estimated in Section 4.2.1.1.3.

The mass of waste airborne from the spill of overburden into the tank (blocks 12 and 13 to block 14, from the model of Figure 23) is derived from two sources:

1. Liquid splashed from the impact of the solid debris on the liquid surface, and

2. Liquid sheared from the surface by aerodynamic entrainment (block 10 of the Figure 23 model). The bounding aerodynamic entrainment of liquids due to passage of air across its surface at $50 \mathrm{mph}$ is reported in DOE-HDBK-3010-94 as $9 \mathrm{E}-5 / \mathrm{hr}(1.5 \mathrm{E}-$ $6 / \mathrm{min}$ ). The mechanism only affects a shallow film on the surface of the liquid. If it is conservatively assumed that flow/turbulence affects a $1-\mathrm{cm}$ deep layer at the surface $\left(4418 \mathrm{ft}^{2} \times 929 \mathrm{cml} / \mathrm{ft}^{2}=4 . \mathrm{IE}+6 \mathrm{~cm} 2\right)$ of the liquid for 1 minute, the airborne release would be: $[1.5 \mathrm{E}-6]\left[4.1 \mathrm{E}+6 \mathrm{~cm}^{2}\right]\left[1.3 \mathrm{~g} / \mathrm{cm}^{3}\right]=\sim 8 \mathrm{~g}$ airborne.

We use peak pressure calculated by previous analysis to estimate the integrated flow out the large opening (block 7), and the activity released by that path (block 15). These calculations consumed all of the available hydrogen before assuming 'dome failure,' and therefore represent the entire deflagration energy input. The failure pressure for the tank dome is estimated at $60 \mathrm{psig}(75 \mathrm{psia}$.) 


$$
\begin{aligned}
& \mathrm{V}_{\mathrm{e}}=\text { volume vented } \mathrm{t} \text { maintain pressiure } \\
& \mathrm{p}_{\mathrm{t}}=\text { max pressure }=60+14.7=75 \mathrm{psia} \\
& \mathrm{p}_{2}=\text { final pressure }=14.7 \mathrm{psia} \\
& \mathrm{V}_{1}=\text { tank free volume }=40,000 \mathrm{ft}^{3} \\
& \mathrm{p}_{1} \mathrm{~V}_{1}=\mathrm{p}_{2} \mathrm{~V}_{2} \\
& \mathrm{~V}_{\mathrm{e}}=\mathrm{V}_{2}-\mathrm{V}_{1}=\mathrm{V}_{1} \times\left[\left(\mathrm{p}_{1} / \mathrm{p}_{2}\right)-1\right] \\
& \mathrm{V}_{\mathrm{e}}=-164,000 \mathrm{ft} 3
\end{aligned}
$$

Thus, $(164,000-40,000) /(164,000)=0.75$ of the initial contents would be expelled during venting. Taking the initial activity in the tank from the above 'initial conditions,' the amount of activity expelled is:

$$
0.75[1.2 \mathrm{E}-2 \mathrm{Ci}+0.385 \mathrm{~g}+8 \mathrm{~g}]=-0.009 \mathrm{Ci} \text { of }{ }^{137} \mathrm{Cs}+6.3 \mathrm{~g} \text { of tank waste. }
$$

\subsubsection{Airborne release of tank atmosphere due to the volume displacement from debris entering the tank after venting}

1. Airborne materials remaining in the tank after venting are $0.25[1.2 \mathrm{E}-2 \mathrm{Ci}+0.385 \mathrm{~g}$ of tank waste $+28 \mathrm{~g}$ of tank waste $]=3 \mathrm{E}-3 \mathrm{Ci}+7 \mathrm{~g}$ of tank waste.

2. The release from a free-fall spill of liquids onto a hard, unyielding surface has been measured. A value of $3.5 \mathrm{E}-3 \mathrm{~kg}$ of particulate material in the respirable size range per $\mathrm{kg}$ of liquid impacted has been estimated for the impact of a $\mathrm{ft}^{2}$ section of concrete with a solid column of soil 10-ft deep. The liquid fraction of liquid impacted that contributes to the generation of particulate is considered to be a layer 1-mm deep (a shallow layer at the surface; liquid under the surface is displaced and any particulate materials generated can not escape into the ambient atmosphere). The material made airborne is based on the area impacted under the $12-\mathrm{ft}$ diameter section that fails, or $113 \mathrm{ft}^{2}$. 
WLC-SD-TWP-R'T-003, Rev. 0

DELPHI Expert Panel Evaluation of Henford High Level Waste Tank F ailure Modes and Fieleasie Quantities

$(3.5 \mathrm{E}-3 \mathrm{~kg} / \mathrm{kg})\left(\left(113 \mathrm{ft}^{2} /\left(0.093 \mathrm{~m}^{2} / \mathrm{ft}^{2}\right)\right) \times\left(0.001 \mathrm{~m} \times 1300 \mathrm{~kg} / \mathrm{m}^{3}\right)=5.52 \mathrm{~kg}\right.$ in the tank free volume

3. The volume of the debris that enters the tank after venting is assumed to be all the debris from the failure of the concrete + the overburden from a $12-\mathrm{ft}$ diameter column:

$$
\begin{aligned}
& \text { Concrete }=0.7854\left[12-\mathrm{ft}^{2} \times[1.25 \mathrm{ft} \text { thick }]=140 \mathrm{ft}^{3}\right. \\
& \text { Soil Overburden }=0.7854[12 \mathrm{ft}]^{2} \times[10 \mathrm{ft}]=1130 \mathrm{ft}^{3} \\
& \text { Total }=140 \mathrm{ft}^{3}+1130 \mathrm{ft}^{3}=\sim 1.3 \mathrm{E}+3 \mathrm{ft}^{3}
\end{aligned}
$$

4. The fraction of the airborne materials released due to the volume displacement resulting from the entry of debris into the tank is:

$$
\left[1300 \mathrm{ft}^{3} / 40,000 \mathrm{ft}^{3}\right][3 \mathrm{E}-3 \mathrm{Ci}+5.52 \mathrm{~kg} \operatorname{tank} \text { waste }]=9.7 \mathrm{E}-4 \mathrm{Ci}+200 \mathrm{~g} \text { tank waste }
$$

\subsubsection{Release of airborne material in the tank free volume due to air passing over the opening (Bernoulli effect)}

For some period after the initial venting, air is drawn into the tank by the volume reduction due to the cooling of the gases in the free volume. At some point, the air temperature equilibrates with the various factors governing the temperature in the tank (e.g., temperature of the metal and concrete liner, temperature of the soil surrounding the tank). The assumed wind for the accident is $1 \mathrm{~m} / \mathrm{s}$ with an F stability. Under such conditions, little force would be exerted to draw the gas in the free volume from the tank. (this is a continuation of block 4 on Figure 24.) As the windspeed increases, Bernoulli's forces and possible direct entry of the air into the tank may expel all remaining airborne materials with time and, as indicated by the existence of airborne activity, other mechanisms may entrain additional materials from the surface of the waste and contamination from the solid surfaces.

\subsubsection{Total release to the air from the DST deflagration model}




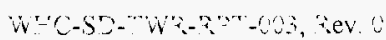

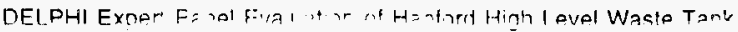
Faiure Mode's and Reléase Quáritities

The release sub-panel estinitics a toca release of about $200 \mathrm{~g}$ of waste from a deflagration in a DST. Due to lack of a dyriamic model and other assumptions and uncertainties, the overall uncertainty on this value is on the order of at least a factor of two to five.

\subsubsection{SST scenario and release}

Figure 24 illustrates the model for calculation of release due to deflagration in an SST. The primary differences from the DST model are due to the mode of failure. The failure mode difference is due to the primary liner in the DST preventing release through concrete cracks. Crack release in SSTs will start at modest pressures, and crack flow area will increase as the pressure rises. Deposition in the cracks and soil greatly reduces activity of gas flowing through the cracks (block 21 on the model). Concrete spalled from cracking will fall into the waste because there is no primary tank to hold it.

\subsubsection{Assumptions}

1. Free volume of tank is $70,000 \mathrm{ft}^{3}$.

2. Tank contents are dry $/$ damp/moist saltcake with a density of $\sim 2.2 \mathrm{~g} / \mathrm{cm}^{3}$.

3. A plume of $\mathrm{H}_{2}$ gas rises from the saltcake due to the radiolysis of water. The $\mathrm{H}_{2}$ mixes with air and deflagrates in the free volume. The deflagration could create an overpressure of $40 \mathrm{psig}$ ( $54 \mathrm{psia}$ ), if the tank did not vent. Based on structural calculations, cracking of the reinforced concrete near the center and "knuckle" regions of the dome will start at 10 to 11 psig. Based on the experimental data for containment structures, the cracks will quickly open to sufficient area to control the pressure rise; we assume to one atmosphere overpressure (14.7 psig), at which point all structural calculations indicate cracking.

4. Concrete is spalled from the interior portion of the dome and impacts the saltcake.

5. The soil overburden (7- to 10-ft deep) is not significantly displaced. 
6. The gases vented from th: tank follow at toitticus path through the exterior, cracked, concrete and the fluidized soil aits as a fluidized bed filter. The total particle capture efficiency of the pathway is assumed to be $99 \%$. (Conservative relative to "Gravel Gertie' results.)

7. The HEPA filter venting the tank and possibly some riser caps are lost.

8. The flow resistance across tank riser paths is less than the resistance across pathway through the cracked concrete and soil overburden. The flow split will depend on flow conditions and the total crack flow area, which will open sufficient to prevent pressure rise beyond one atmosphere. 


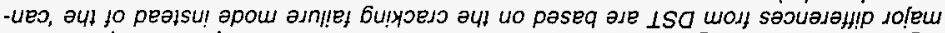

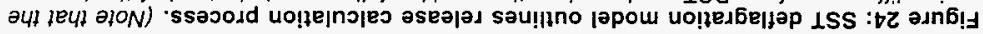

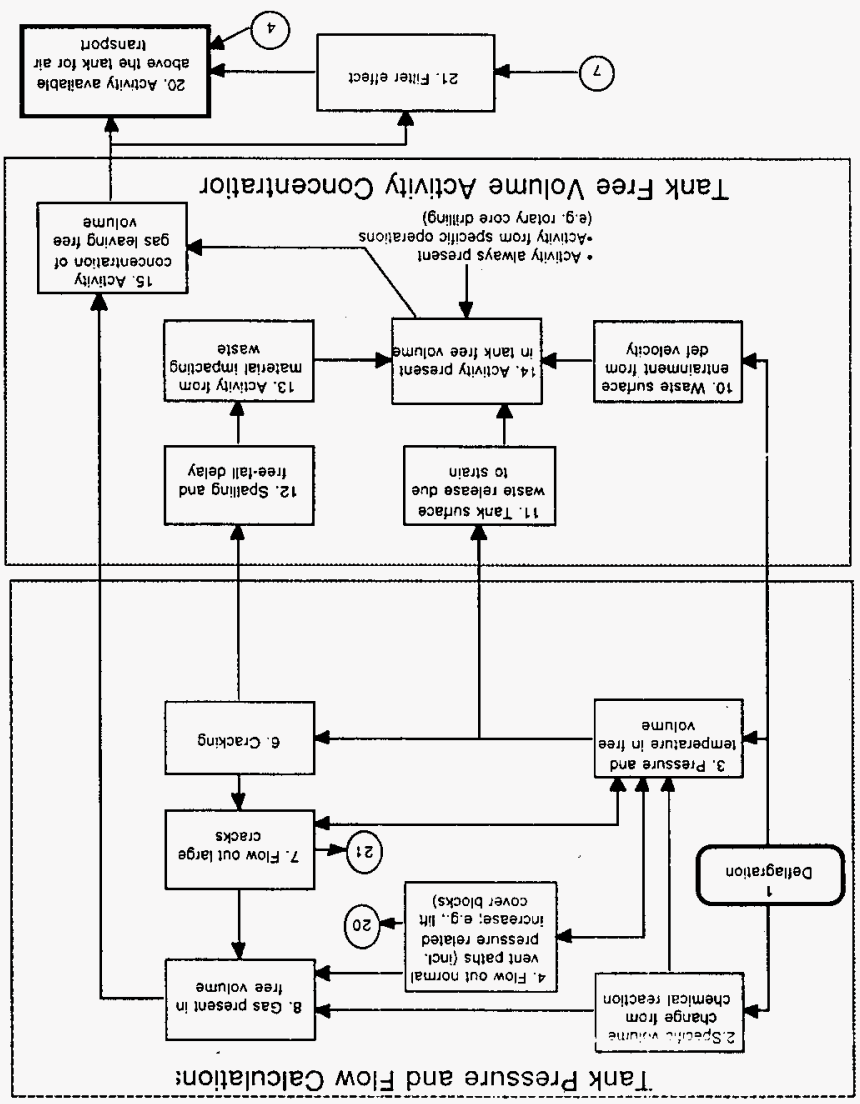




\subsubsection{Release During venting of the tank}

The materials airborne are:

1. The activity present in the tank atmosphere under static situation;

2. The mass of saltcake suspended by any operations being performed (sampling); and

3. The mass of material made airborne by the deflagration.

The mass released from the tank is the mass associated with the volume needed to remove the overpressure.

1. Activity airborne in the free volume prior to venting. Based on the same assumption used for DSTs, the materials airborne in the free volume are $1.1 \mathrm{E}-2 \mathrm{Ci}$ of ${ }^{137} \mathrm{Cs}$ and $0.385 \mathrm{~g}$ of salt. The assumptions quoted from the LANL report are more germane in this situation.

2. Saltcake made airborne by the deflagration.

Aerodynamic Entrainment. The ARF/RF values in DOE-HDBK-3010-94 are for a dry, cohessionless, powder on a heterogeneous substrate at windspeeds up to 20 mph (ARF 4E-5/hr (7E-7/min), RF 1.0. Saltcake is commonly a relatively coherent solid that may be moist to damp at the surface. There are tanks with relatively dry saltcake that may have loose salt crystals on the surface. The windspeeds generated by the deflagration are subsonic and, considering the entire surface of the saltcake, may range from many $\mathrm{m} / \mathrm{s}$ to zero at the farthest points from the deflagration. The calculation assumes an ARF of $7 \mathrm{E}-7 / \mathrm{min}$ for a one minute period.

The total surface area of the saltcake is $4,417 \mathrm{ft}^{2}$ or $4.1 \mathrm{E} 6 \mathrm{~cm}^{2}$. The theoretical density of both sodium nitrate and nitrite is $\sim 2.2 \mathrm{~g} / \mathrm{cm}^{3}$. Assuming the depth of 
WHC-SD-rWR-?P'-003, Rev 0

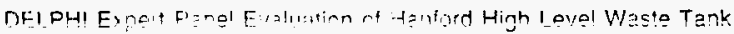
Farlure Modes; and Rele ase Quantities

material that is involved in aerotynamic entrainment is $1-\mathrm{cm}$ (the surface of the saltcake is much rougher han liquild surfaces) the total mass affected would be:

$$
(4.1 \mathrm{E}+6 \mathrm{cni} \text { a } \mathrm{i}-\imath 111)\left(2.2 \mathrm{~g} / \mathrm{cm}^{3}\right)=9.02 \mathrm{E}+6 \mathrm{~g}
$$

The mass airborne in the respirable size range is:

$$
(7 \mathrm{E}-7)(9.02 \mathrm{E}+6 \mathrm{~g})=6.3 \mathrm{~g}
$$

Dried surface contamination shaken from the tank liner during pressurizationdepressurization. As cited in the Double-Shell Tank scenario, an unevaluated mass of dried salt may be made airborne by the mechanism.

Fraction of free volume vented to relieve overpressure. The potential overpressure with no venting results in a volume equal to $54 \mathrm{psia} / 14.7 \mathrm{psia}=3.7$ atmosphere. The fraction vented to reduce the pressure to 1 atmosphere is:

$$
\text { (3.7-1) atm } / 3.7 \mathrm{~atm}=0.73 \text {. }
$$

The activity and mass released during the venting is:

$$
0.73 \times\left(1.1 \mathrm{E}-2 \mathrm{Ci}{ }^{137} \mathrm{Cs}+0.385 \mathrm{~g}+6.3 \mathrm{~g}\right)=8 \mathrm{E}-3 \mathrm{Ci}{ }^{137} \mathrm{Cs}+4.9 \mathrm{~g} .
$$

\subsubsection{Airborne release of tank atmosphere due to the volume displacement from concrete spalled from the interior of the SST dome}

1. The activity from mass remaining in the tank atmosphere after pressure venting is:

$$
(1-0.73) \times\left[\left(1.1 \mathrm{E}-2 \mathrm{Ci}{ }^{1.7} \mathrm{Cs}\right)+(0.385+6.3 \mathrm{~g})\right]=5 \mathrm{E}-3 \mathrm{Ci}{ }^{137} \mathrm{Cs}+1.8 \mathrm{~g}
$$

2. The mass made airborne by the impact of the concrete spalled from the interior of the dome is estimated assuming: 
A. Density of concrete 150 pounds/ft ${ }^{3}$

B. The size of the concrete that impacts the saltcake surface is equivalent to one $\mathrm{ft}^{2}$ pieces and that the concrete penetration behaves as artillery projectiles impacting soil. [This yields the depth for calculation of the material airborne in the tank free volume.]

C. Airborne suspension in the tank free volume uses the formula for powder suspension correlation as a function of energy imparted to the material in DOEHDBK-3010-94 for 25-ft fall distance (block 12 of Figure 24).

D. Quantity of material spalled and area of waste impacted (block 13 of Figure 24 model) is determined based on the vent area required to terminate the pressure rise, a crack width of one centimeter, and spalled chunks equal to blocks one half the distance between rebar.

E. The pressure rise in an unvented SST would reach $40 \mathrm{psig}$ in $0.5 \mathrm{~s}^{54}$

F. Tank cracks remain open.

G. The total crack flow area is (block 6 of Figure 24 model) based on limiting the pressure in the tank to one atmosphere gage ${ }^{55}$. [This should yield a conservative quantity of concrete spalled. Experimental data indicates very little actual spalling.]

H. Ratio of the fraction of released material that exits through the filtered path to the total is variable (blocks 4 and 7 of Figure 24). (While the flow area through the filtered path can be arbitrarily large, the resistance will be higher than through the Unfiltered paths.) 
WHC-SD-TWR-RPT-003, Rev. 0

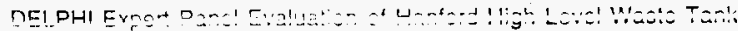

Failure Modes and Release Quantities

I. No credit is taken for settling of the lofted waste material or the distribution in the free volume (i.e. higher concentration near the waste surface, while the released material is from the top of the tank).

J. Neglect the small initial ${ }^{137} \mathrm{Cs}$ contribution.

The energy density of blocks that fall 25 feet is $\sim 0.62 \mathrm{~J} / \mathrm{cm}^{3}$ resulting in an[ARF][RF] of 3E-4.

We determine the crack area by area needed to vent enough gas to maintain the tank at less than 14.7 psig in 0.5 seconds, the time of the calculated pressure rise. We calculate crack length with the assumption of a $1 \mathrm{~cm}$ wide crack. Then, we define the spalled area as the crack length times half the rebar spacing.

$A=$ total crack area

$\mathrm{S}=$ total surface area of waste impacted, $\mathrm{ft}^{2}$

$\mathrm{V}_{\mathrm{e}}=$ volume vented to maintain pressure

$\mathrm{v}=$ velocity of vented material $=1.100 \mathrm{ft} / \mathrm{s}$ (sonic at one atmosphere)

$\mathrm{p}_{1}=\max$ pressure $=40+14.7=54.7 \mathrm{psia}$

$\mathrm{p}_{2}=$ final pressure $=14.7+14.7=29.4$ psia

$\mathrm{V}_{1}=\operatorname{tank}$ free volume $=70,000 \mathrm{ft}^{3}$

$\mathrm{p}_{1} \mathrm{~V}_{1}=\mathrm{p}_{2} \mathrm{~V}_{2}$

$V_{e}=V_{2}-V_{1}=V_{1} x\left[\left(p_{1} / p_{2}\right)-1\right]$

$V_{e}=\sim 60,000 \mathrm{ft} 3$

Since,

$\mathrm{V}_{\mathrm{c}}=\mathrm{A} \vee \Delta \mathrm{t}$, and $\Delta \mathrm{t}=0.5 \mathrm{~s}$,

$A=V_{e} /(.5 \times v)=-110 \mathrm{ft}^{2}$ 
WHC-SD-TWR-RPT-003, Rev. 0

DELPHI Expert Panel Evaluation of Hanford High Level Waste Tank

Failure Modes and Release Quantities

The total surface area of waste impacted is equal to the total surface area of concrete spalled. The crack width is assumed to be $1 \mathrm{~cm}$, so the overall crack length is $[\mathrm{A} /(\mathrm{lm})]$. The spall around the crack is assumed to be half the distance between the rebar. The nominal rebar spacing is 12 ". Therefore,

$$
\begin{aligned}
& S=[A /(1 \mathrm{~cm})] \times[(1 / 2) \times(\text { length between rebar })] \\
& S=\sim 1,700 \mathrm{ft}^{2}=150 \mathrm{~m}^{2}
\end{aligned}
$$

Assuming concrete chunks impact the surface $S\left(150 \mathrm{~m}^{2}\right)$ to a depth

of $0.0427 \mathrm{~m}$ (Ref. $^{56}$ ) (Any additional material from these same locations impacting the surface would impact the concrete debris, not the saltcake). The total mass of the material affected is:

$$
\left[6.4 \mathrm{~m}^{2}\right]\left[10^{6} \mathrm{~cm}^{3} / \mathrm{m}^{3}\right]\left[2.2 \mathrm{~g} / \mathrm{cm}^{3}\right]=1.4 \mathrm{E}+7 \mathrm{~g}
$$

The airborne release to the tank free volume is:

$$
\mathrm{M}^{\prime}=[3 \mathrm{E}-4](1.4 \mathrm{E}+7 \mathrm{~g}]=4,200 \mathrm{~g}
$$

3. Material vented due to displacement of the free volume by the concrete volume (in reality, there is no volume displacement - the concrete lost from the dome interior is equal to the volume of the concrete debris) is:

$$
\begin{aligned}
& M_{v}=M^{\prime} x \text { (volume of concrete / tank free volume) } \\
& M_{v}=[2.7 \mathrm{~g}+4,200 \mathrm{~g}]\left[\left(1,700 / 2 \mathrm{ft}^{3}\right) / 70,000 \mathrm{ft}^{3}\right]=\sim 50 \mathrm{~g}
\end{aligned}
$$

4. Some of the material vented exits through the 'filtered release' path of the cracked concrete, and some may exit through unfiltered paths such as a failed HEPA filter or damaged riser caps, including lifting of the large riser cover block. 


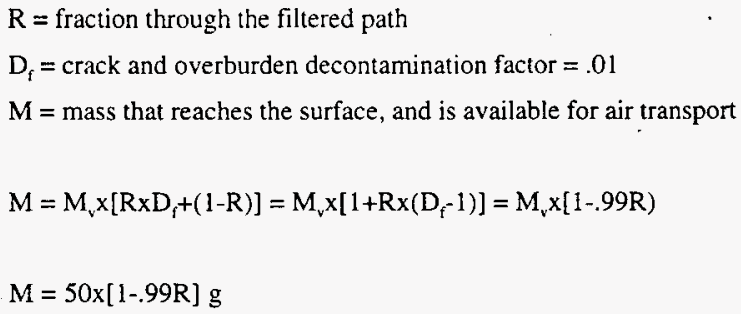

The area of a 42 " riser is about $10 \mathrm{ft}^{2}$. The crack flow area is ten times this, so about $90 \%$ of the gas should leave through the cracks. With $\mathrm{R}=.9, \mathrm{M}=\sim 0.5 \mathrm{~g}$. While flow resistance through the cracks and soil will likely be higher than through the riser, if the flow is critical this will not matter. If the flow area is insufficient to reduce the pressure rise, the increasing pressure will increase the total crack flow area, until maximum pressure is reached. Prediction of the pressure and flow area, and the consequent impact of spalled material on the waste requires a dynamic, mechanistic model.

Reviewers might consider that the timing of the spalling would be before the pressurized release. With the assumed $0.5 \mathrm{~s}$ pressure release time, free-fall distance is only $4 \mathrm{ft}$. Therefore, the concrete would not have time to impact the waste before the hole opens. Therefore the gas release would not include the additional waste from tank spalling. Slower pressure rise times, associated, for example, with liquid burns, may lead to a situation where there is time for concrete to fall during the pressurized release phase. In this case, the crack area necessary to relieve the pressure (and thus spalling) would be less. Even if approximately one half (because only half the gas volume leaves to reduce pressure) of the $4,200 \mathrm{~g}$ would be released from the tank, at least $90 \%$ would go through the vented path, so $-20 \mathrm{~g}$ would be available for atmospheric transport.

\subsubsection{Release of airborne material in the tank free volume due to air passing over openings}

The size of the unfiltered opening postulated (4-inch pipe to 42-inch riser) at the windspeed postulated for the event ( $1 \mathrm{rn} / \mathrm{s}$, F Stability class) would extract an insignificant fraction of 
the free volume with time. Dilution would tend to be exponential and diurnal variation would also result in inflow as the temperature decreased.

\subsubsection{Total release for the SST deflagration scenario}

The calculated total release for the SST deflagration event from as little as $0.5 \mathrm{~g}$ to about 20 g. The panel estimated that the (one standard deviation) uncertainty in the release quantity for flammable gas deflagration (See Table 3 ) is about five times the nominal release quantity. This was prior to assessment of the new failure mode, and therefore was based on a higher nominal release. A reasonable estimate of the uncertainty for the new release would be a factor of ten to twenty.

A reasonable release value for comparison with previous calculations is $<1 \mathrm{~kg}$ of release to the air. Since $1 \mathrm{~kg}$ is conservative relative to the quantity calculated, uncertainty of less than a factor of 10 should be associated with this estimate.

\subsection{Release findings and recommendations}

1. Calculated release quantities are very low compared to the previous WHC and LANL calculations for dome collapse cases. The reason is that dome collapse was not assumed.

2. A dynamic model, including tank cracking and filtered release, should be used for the FSAR calculations. This model will facilitate connecting event driving forces, tank dynamic response (cracking), and release phenomena. It will also facilitate sensitivity analysis.

3. Based on the scoping calculations performed, calculated releases to the atmosphere should be less than $1 \mathrm{~kg}$.

4. The panel could not estimate potential release for organic burns because the consequence model is not sufficiently detailed to define tank failure modes. 


\section{Conclusions and Recommendations}

\subsection{Conclusions}

Be aware of the following cautions on the use of any structural numbers/estimates:

- The conclusions are applicable only to failure analysis/limits.

- The conclusions do not address code compliance (ACI, ASCE, ASME, UBC). In most cases, many code limits will be violated.

- The panel assumed best estimate material properties.

- The panel assumed the structure would not be serviceable after the event/load.

Therefore, these conclusions can NOT Apply for Operational Limits. (Significant permanent damage would compromise operational load capabilities.)

\subsubsection{Failure Modes}

1. Dome collapse is not the appropriate Hanford Tank failure mode for postulated initiators and scenarios. The panel bases this conclusion on knowledge of the vast amount of structural analysis performed on the Hanford tanks, and on failure modes of real tanks observed in the world. Instead of assuming dome collapse, they examined each scenario type for the appropriate failure mode and fragility limits. The panel was unable to locate supporting technical basis for dome collapse.

2.(a) Tank failure due to uniform Ioading (i.e., excess overburden) would require an additional 30 feet of soil. The most likely failure mode would be progressive tensile failure of the haunch region or failure at the upper wall. The experts concluded that the dome would settle into the waste in large (potentially only one) piece. 


\section{2.(b) A load drop of $200,000 \mathrm{ft}$. \# in the pump pit area could lead to localized perforation of the dome.}

2.(c) The loads necessary to create tank failure for concentrated load are 300-600 tons for the SSTs and $400-800$ tons for the DSTs. The panel expects that concentrated loads and excess overburden of these magnitudes are beyond extremely unlikely events. No known movable object on or near the Hanford site would provide these loads. The failure mode in these cases would be shear failure of a disk in the dome of the tank.

3. Aging is not a primary failure mechanism for the Hanford tanks. It should be considered in determining failure limits.

4.(a) The DST internal pressure failure mode is the opening of a 12-foot semicircular 'can-opener' tab at top center of the tank, along with potential lifting of the entire tank. The expert panel substantiated this conclusion based on tank design features and previous tank structural analysis. Some of the DSTs do not have the side wall connected to the base mat, and may experience some upward movement before failure. The tank fails at the ring in the center because it is the weakest point. The liner has a weld there, and the large riser provides stress intensification. Also, the rebar overlaps in this area, causing the weakest concrete tension failure location. The failure will most likely lift one side of the disk while it remains connected on the other side because of internal pressure relief during the opening. This opening will occur at about 60 psig. The limited quantity of material available to fall into the tank, little internal driving force after pressure relief, and the vertical rise needed to create an air release would limit the release.

4.(b) The SST internal pressure failure mode is cracking in the sidewall below the haunch and toward the center of the dome. The expert panel based this conclusion on tank design features, previous structural analysis, and evaluation of real failures. The sidewall below the haunch is the weakest point in terms of internal pressure. The SST liner does not extend to cover the dome. The dome cracks from 
strain. Through-wall cracks will occur at about 11 psig. Cracks and soil would filter releases. Since there is uncertainty in the deflagration pressure calculations, FSAR analysis must consider extension of this failure mode to higher pressures.

5. The release experts estimated release quantities $<1 \mathrm{~kg}$ for the identified release scenarios, excepting the organic nitrate burn. (See recommendation 1) The release panel calculated this result using the identified failure modes and previous data. They performed the calculations for an SST release and for a DST release. The SST air release, other than through the risers, is very small due to soil filtering of the release. The assumption of the quantity of suspended particulate in the tank gas volume prior to release dominates DST release. The calculation assumed a high quantity of suspended particulate that could only be appropriate during the conduct of rotary mode sampling.

6. Seismic fragility limits indicate the tanks can withstand accelerations far above the design limit. Hanford seismic design acceleration is $0.2 \mathrm{~g}$. The SST fragility 'limit' is estimated as $0.6 \mathrm{~g}$, and the DST 'limit' is estimated at $0.8 \mathrm{~g}$. The word limit is in quotes because fragility is not a specific number, but a range in which the number of tanks likely to fail is larger as the acceleration increases. This is due to minor differences in the tanks, contents, soil, and locations, and the fact that failure is thought to be a stochastic event. Smaller events may cause spalling of internal concrete in limited quantity. Dome failure is unlikely for accelerations up to $1.5 \mathrm{~g}$.

\subsubsection{Sensitivities}

\section{Failure modes and fragilities are the most significant determinants of release} quantity. They determine if the correct problem is being analyzed. The team did not examine the assumptions and methods for calculation of tank pressure loading from flammable gas or organic liquid burns. Within the release quantity calculation, the most sensitive assumptions and parameters relate to the quantity of waste lofted into the tank free volume, making the waste available for release. 
WHC-SD-TWR-RPT-003, Rev. 0

DELPHI Expert Panel Evaluation of Hantord High Level Waste Tank

Failure Modes and Release Quantities

\subsubsection{Release Quantities}

Results from sample calculations with the recommended approach yield much smaller quantilies of waste for airborne trunsport than either of the previous studies. This report presents sample calculation approaches for the two failure modes likely to result in significant airborne release. The panel recommends an integrated dynamic system model for the FSAR analysis.

\subsection{Recommendation}

1. The panel recommends further evaluation of organic nitrate burns. A major organic nitrate burn could cause other failure mechanisms (degradation of concrete and rebar) due to extreme tank material temperatures. The credibility of this event should be examined before performing more detailed analysis. Comparisons between the Hanford tanks and the SRS tanks in regard to this potential event should be explored. If this event is judged credible, more detailed thermal analysis is required, perhaps coupled with structural evaluation, to determine the appropriate failure mode and release.

2. The panel recommends using a system approach to perform the accident analyses. They recommend using explicit mechanistic models which are logically consistent. Analysts should specifically identify uncertainties in models and data, rather than using unrealistic assumptions. 


\section{References}

'LA-UR-96-36, ReV. 0. A SAFETY ASSE JjVIENI UF KUTARY MODE CORE SAMPLING IN FLAMMABLE SINGLE SHELL TANKS: HANFORD SITE, RICHLAND, WASHINGTON, February 23, 1996

${ }^{2}$ WHC-SD-WM-SAR-065 Rev. 0, Volume 2, Interim Chapter 3.0 Hazard and Accident Analysis

${ }^{3}$ Nadler, Gerald and Hibino, Shozo, BREAKTHROUGH THINKING, Why We Must Change The Way We Solve Problems, And The Seven Principles To Achieve This, Prima Publishing, New York, 1990.

${ }^{4}$ Tregoe, Benjamin B. and Kepner, Charles H., The Rational Manager, A Systematic Approach to Problem Solving and Decision Making, Kepner-Tregoe Inc., Princeton, N.J., 1965

${ }^{5}$ Carro, Craig, Memo to Larry Kripps, 3/20/95

${ }^{6}$ Marusich, Robert, DOME COLLAPSE CONSEQUENCES, Presentation to Delphi panel, April 8, 1996

${ }^{7}$ McFarlane, D. R. et. al., "PROBABILISTIC SAFETY ASSESSMENT FOR

HANFORD HIGH-LEVEL WASTE TANKS," LA-UR-95-1900, October, 1995

${ }^{8}$ Linsonte, Harold A., Chapter VII, Eight Basic Pitfalls: A Checklist

${ }^{9}$ Nadler, Gerald and Hibino, Shozo, BREAKTHROUGH THINKING. Why We Must Change The Way We Solve Problems, And The Seven Principles To Achieve This, Prima Publishing, New York, 1990

${ }^{10}$ Hora, Stephen C., Acquisition of Expert Judgment: Examples From Risk Assessment,

"Berdie, Douglas, R., and Anderson, John F., QUESTIONNAIRES: Design and Use, Scarecrow Press, Metuchin, N. J., 1974

${ }^{12}$ Excerpt from the Westinghouse Document WHC-SD-WM-SAR-065 REV 0

${ }^{13}$ Appendix I, Dome Collapse Accidents, LA-UR-96-36

14 Appendix I, Dome Collapse Accidents, LA-UR-96-36

${ }^{15}$ Excerpt from the Westinghouse Document WHC-SD-WM-SAR-065 REV 0

${ }^{16}$ ARH, 1969, Model Test of Waste Disposal Tanks, ARH-R-47, test performed by Wiss, Janney, Elstner and Associates for Atlantic Richfield Hanford Company, Richland, Washington

${ }^{17}$ WHC, 1993, Tank 241-C-106 Structural Integrity Evaluation for In Situ Conditions, WHC-SD-W320-ANAL-001, Rev. 0, compiled by L. J. Julyk, Westinghouse Hanford Company, Richland, Washington

${ }^{18}$ Murphy, Leonard M., "San Fernando. California Earthquake of February 9, 1971," U.S. Department of Commerce, 1973

${ }^{19}$ K.M. Cole, G.E. Albritton, and J.E. Beavers, "RESPONSE OF DEEP TWO-WAYREINFORCED AND UNREINFORCED CONCRETE SLABS TO STATIC AND DYNAMIC LOADING," Technical report N-69-2, November, 1969

20) Albritton, G.E., J.P. Balsara, and D.M. Bayer, "RESPONSE OF DEEP TWO-WAY REINFORCED AND UNREINFORCED CONCRETE SLABS TO STATIC AND DYNAMIC LOADING," Technical Report N-69-2, November, 1969. 
${ }^{21}$ Albritton, G.E., J.P. Balsara, and D.M. Bayer, "RESPONSE OF DEEP TWO-WAY REINFORCED AND UNREINFORCED CONCRETE SLABS TO STATIC AND DYNAMIC LOADING," Technical Report N-69-2, November, 1969.

${ }^{22}$ Horschel, D. S., "Experimental Result from Pressure Tecting a 1:6 Scale Nuclear Power Plant Containment," NUREG/CR-5121, SAND88-0906, Sandia National Laboratories, Albuquerque, NM, December 1991

${ }^{2.3}$ Reference: Palfrey, J. and Smith. J.C. W., "Ultimate Load Test of a 1/10 the Scale Model Prestressed Concrete Containment, Transactions of the Eleventh International Conference on Structural Mechanics in Reactor Technology, Volume H10/6, Tokyo, Japan, August 1991.

${ }^{24}$ Sullivan, Harold L., "A Safety Assessment for Evaluating the Efficacy of Pump Mixing to Mitigate Episodic Gas Releases in Tank 241-101-SY: Hanford Site, Richland, Washington." LA-UR-92-3196 (Rev. 14), 3/31/95

${ }^{25}$ WHC-SD-WM-DA-150, Rev. 0, "Structural Sensitivity Evaluations of Single- and Double-Sell Waste Tanks for Accelerated Safety analysis - Phase 1", Westinghouse Hanford Company. Richland Washington, 1994.

${ }^{26}$ WHC-SD-WM-SARR-032-Vols. I and II, "ASA Structural Analysis - Phase II, Westinghouse Hanford Company, Richland Washington, 199?.

${ }^{27}$ WHC-SD-WM-DA-150, Rev. 0, "Structural Sensitivity Evaluations of Single- and Double-Sell Waste Tanks for Accelerated Safety analysis - Phase 1", Westinghouse Hanford Company, Richland Washington, 1994.

${ }^{28}$ WHC-SD-WM-SARR-032-Vols. I and II, "ASA Structural Analysis - Phase II, Westinghouse Hanford Company, Richland Washington, 199 ?

${ }^{29}$ Leach, C.E., 1993, Hanford Site Tank Farm Facilities Interim Safety Basis, WHC-SD-WM-ISB-001, Rev. 0., Westinghouse Hanford Company, Richland, Washington

${ }^{30}$ RHO, 1978, Analysis of Underground Waste Storage Tanks 241 -AX at Hanford Washington, RHO-R-6, by JRS Blume and Associates, San Francisco, California.

${ }^{31}$ Ramble, 1983, Single-Shell Waste Tanks Load Sensitivity Study, SD-RE-TI-012, Rev. A-0, Rockwell Hanford Operations, Richland, Washington.

${ }^{32}$ Leach, C.E., 1993, Hanford Site Tank Farm Facilities Interim Safety Basis, WHC-SD-WM-ISB-001, Rev. 0., Westinghouse Hanford Company, Richland, Washington

${ }^{33}$ Backer, D. L, 1994, Single - and Double-Shell Tanks Load Report for Accelerated Safety analysis, WHC-SD-WM-ES-286, Rev. 0.

${ }^{34}$ Mercier, P. F.. M. D. Wonacott, and C. DeFigh-Price, 1981, Survey of the Single-Shell Tank Thermal Histories, RHO-CD-1172, Rockwell Hanford Operations, Richland, Washington

${ }^{35}$ WHC, 1994, Staric Intemal Pressure Capacity of Hanford Single-Shell Waste Storage Tanks, WHC-SD-WM-Tl-623, Rev. 0, prepared by ADVENT Engineering Services, Inc., and Westinghouse Hanford Company, Richland, Washington.

${ }^{36}$ WHC-SD-WM-TI-465

37. "A Safety Assessment for Evaluating the Efficacy of Pump Mixing to Mitigate Episodic Gas Releases Tank 24I-101-SY: Hanford Site, Richland, Washington." June 19, 1992 (Draft). 
${ }^{38}$ AS $\wedge$ Phase I. Fisher, T.W.. et al, 1994. Stwictural Sensitivity Evaluations of Single- and Double-Shell Waste Tanks for Accelerated Safety analysis - Phase I, WHC-SD-WM-DA150, Rev. 0, Westinghouse Hanford Company, Richland, Washington.

${ }^{39}$ Accelerated Safety analysis-Structural Analyses, Phase I-Structural sensitivity Evaluation of Single-and Double-Shell Waste Storage Tanks, WHC-SD-WM-SARR-012, Rev. 1 (1994)

${ }^{40}$ Structural Sensitivity Evaluation of Single-and Double-Shell Waste Tanks for Accelerated Safety Analysis-Phase I, WHC-SD-WM-DA-150 (1994)

${ }^{41}$ RHO, 1978a, Analysis of Underground Waste Storage Tank 241-AX at Hanford, Washington, RHO-R-6, URS/John A. Blume and Associates, Engineers, Vitro Engineering, Richland, Washington.

${ }^{42}$ DOE, 1994, Natural Phenomena Hazards design and Evaluation Criteria for Deparme'm of Encryy Facilities, DOE-STD-1020-94, Washington, D.C., April.

${ }^{43}$ UCRL-15910. 1990. Design and Evaluation Guidelines for Department of Energy Facilities Subjected to Natural Phenomena Hazards, UCRL-15910, University of California Research Laboratory, Livermore, CA

${ }^{44}$ BNL. 1993, K. Bandyopadhyay, et al., Seismic Design and Evaluation Guidelines for the Department of Energy High-Level Waste Storage Tanks and Appurtenances, BNL 52361 , U.S. Department of Energy, Brookhaven National Laboratories, Associated Universities, Inc., Upton, New York, New York

${ }^{45} \mathrm{ACI}, 1983$, Zarghamee, M.S., and F.J. Heger, Buckling of Thin Concrete Domes, ACE Journal Technical Paper Title No. 80-45, November 1983, p 487

${ }^{46} \mathrm{ARH}, 1976$, Structural Evaluation of Proposed 241-AW Tanks: Phase I - Investigation of Effect of Criteria Changes, ARH-R-218, URS/John A. Blume and Associates, Engineers, Atlantic-Richfield Hanford Company, Richland, Washington, February. ${ }^{47}$ ARH, 1976, Analysis of Underground Waste Storage Tanks 24l-AW at Hanford, Washington, ARH-R-219, URS/John A. Blume and Associates, Engineers, AtlanticRichfield Hanford Company. Richland, Washington, July.

${ }^{48}$ EQE, 1993, Probabilistic Capacity of the 241-AX Underground Waste Storage Tanks to Withstand Seismic Excitation, EQE Engineering Consultants, January.

${ }^{49}$ Fisher, T. W. L. L. Hyde, C. J. Moore, S. W. Peterson, W. W. Chen, 1994, Structural Sensitivity Evaluations of Single- and Double-Shell Waste Tanks for Accelerated Safety analysis - Phase 1, WHC-SD-WM-DA-150, Rev. 0, Westinghouse Hanford Company, Richland, Washington

${ }^{50}$ RHO 1978b, Additional Analysis of Underground Waste Storage Tanks 241-AW, Hanford, Washington, RHO-C-17, URS/John A. Blume and Associates, Engineers, Vitro Engineering, Richland, Washington.

51 Julyk. L.J., 1994. Analysis of Underground Waste Storage Tanks 241-SY at Hanford, Washington, ARH-R-172, Rev. 0A, Westinghouse Hanford Company, Richland, Washington, August.

52 Bandyopadhyay, K., A. Cornell. C. Costantino, R. Kennedy, C. Miller, and A. Veletsos, 1995, Seismic Design and Evaluation Guidelines for the Department of Energy High-level Waste Tanks and Appurtenances, BNL 52361, Brookhaven National Laboratory, Associated Universities, Inc.. October. 
${ }^{53}$ RHO, 1981, A Comprehensive Summary of the Analysis of the 241-AW Underground Waste Storage Tanks, Hanford, Washington, RHO-C-60, UR.S/John A. Blume and Associates, Engineers, Vitro Engineering, Richland, Washington.

${ }^{54}$ Personal communication, Bob Marusich, WHC to L. Leach, 5/6/96

${ }^{55}$ Letter, M. Grigsby to Bob Marusich, MSIN: A2-34, Dated March 1, 1996

${ }^{56}$ Calculation from artillery projection model for $25 \mathrm{ft}$ fall energy. Communication from Bob Marusich, WHC to Jofu Mishima, SAIC, April, 1996 


\section{DISTRIBUTION SHEET}

\begin{tabular}{|c|c|c|c|c|c|}
\hline \multirow{2}{*}{$\begin{array}{l}\text { To } \\
\text { Distribution }\end{array}$} & \multirow{2}{*}{\multicolumn{3}{|c|}{$\begin{array}{l}\text { From } \\
\text { TWRS FSAR DEVELOPMENT }\end{array}$}} & \multicolumn{2}{|l|}{ Page 1 of 1} \\
\hline & & & & \multicolumn{2}{|c|}{ Date $09 / 25 / 96$} \\
\hline \multicolumn{4}{|l|}{ Project Title/Work Order } & \multicolumn{2}{|c|}{ EDT No. 606489} \\
\hline \multicolumn{4}{|c|}{$\begin{array}{l}\text { DELPHI Expert Panel Evaluation of Hanford High Level Waste Tank } \\
\text { Failure Modes and Release Quantities }\end{array}$} & \multicolumn{2}{|c|}{ ECN No. $N / A$} \\
\hline Name & MSIN & $\begin{array}{c}\text { Text } \\
\text { With All } \\
\text { Attach. }\end{array}$ & Text Only & $\begin{array}{l}\text { Attach./ } \\
\text { Appendix } \\
\text { Only }\end{array}$ & $\begin{array}{l}\text { EDT/ECN } \\
\text { Only }\end{array}$ \\
\hline
\end{tabular}

WHC

G.L. Dunford

F.C. Han

M.D. Hassebrock

L.J. Julyk

R.M. Marusich

S.H. Rifaey

P.L. Smith

Central Files

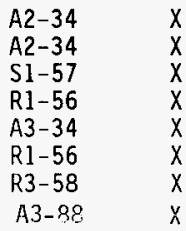

